\title{
Effectiveness of blended instructional design based on active learning in a graphic engineering course
}

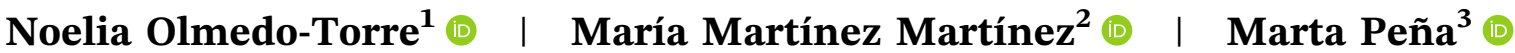

\author{
${ }^{1}$ Department of Graphic and Design \\ Engineering, Universitat Politècnica de \\ Catalunya-BarcelonaTech, \\ Barcelona, Spain \\ ${ }^{2}$ Department of Chemical Engineering, \\ Universitat Politècnica de Catalunya- \\ BarcelonaTech, Barcelona, Spain \\ ${ }^{3}$ Department of Mathematics, Universitat \\ Politècnica de Catalunya-BarcelonaTech, \\ Barcelona, Spain
}

Correspondence

Marta Peña, Department of Mathematics, Universitat Politècnica de CatalunyaBarcelonaTech, Av. Diagonal 647, 08028 Barcelona, Spain.

Email: marta.penya@upc.edu

\begin{abstract}
Encouraging the use of active-learning methodologies, both inside and outside the classroom by means of planned activities, is a key factor in effective learning, as well as being essential for students to achieve the goals set for each subject by making them responsible for their own learning. In this longitudinal and quantitative study, we describe the different active learning activities, such as Flipped Classroom, Design Thinking, Visual Thinking, and Project-Based Learning (PBL), undertaken from 2015 to 2018 in the compulsory subject Graphic Expression imparted during the first year from all the degree studies of the Escola d'Enginyeria de Barcelona Est from Universitat Politècnica de Catalunya-UPC BarcelonaTech. The introduction of active-learning teaching methodologies for the solving of problems with computer aided design throughout the course, with increasing complexity of exercise completion, has led to a significant improvement in academic results by students in this subject. The results show that the inclusion of these methodologies improves student learning, as seen through the group development of an engineering project presented on the conclusion of the course. PBL is the methodology that is most highly appreciated by students because it enables them to integrate all the skills and knowledge acquired throughout the course and is also the activity in which they obtain the best marks.
\end{abstract}

\section{K E Y W O R D S}

active learning, assessment, engineering degree, graphic engineering

\section{INTRODUCTION}

The planning for subjects in the new European Higher Education Area (EHEA) degree courses involves three vital factors: student-centered learning; the acquisition of learning goals based on the competences, assessment, and monitoring of the learning activities using the European Credit Transfer System (ECTS) [1]. With this approach, teachers design learning activities on the basis of the goals to be reached, guide students through the learning process, apply active methodologies in which students themselves are the agents responsible for their own learning, and lastly, employ assessment strategies that enable the acquisition of the said competences to be measured [20,44,66,75].

The choice of appropriate learning activities in and out of the classroom takes into account several components described by Johnson [46] where the student must be able to face problems in which they must structure their thinking and strive (always with the help of the teacher) to find practical solutions. These components are: the application scenario, group work, problem-solving, discovering 
new knowledge, and finally, application to the world of work. The decision to incorporate active methodologies seeks to generate significant changes in and out of the classroom, as it seeks to set aside traditional training in such a way that it improves student learning by giving tools that generate spaces for reflection on what has been learned, but above all help students to understand abstract and complex concepts. With the application of the Flipped Classroom (FC) methodology, the learning process is sought through direct individual instruction based on computers with activities in and outside of class. The application of the Design Thinking (DT) methodology seeks a useful process for the creative resolution of pieces in graphic engineering. It is useful for problems that are poorly defined or complicated and for analyzing a problem and its context and reinterpreting it to find a way to a solution. Visual Thinking (VT) allows the formation of mental models and the creation of images in space that can later be transferred to paper. Finally, project-based learning (PBL) is used as a facilitator in the integration of the learning results of the other methodologies through satisfaction in the construction of an engineering project. The aim is to promote the implementation and organization of teamwork, the establishment of leadership roles, and the integration of students in multidisciplinary projects.

There are numerous studies supporting the positive effects of active learning in improving student motivation and attitudes. Among teaching methodologies, active learning is one of the most preferred and empirically endorsed practices in regular classroom teaching $[3,12,33,72]$, but it can only be acquired through the involvement, motivation, attention, and constant work of the students [22,78]. The benefits of active learning are well-documented and proven, both in overall student learning and in reducing gaps in marks, achievement, and failure rates between underrepresented groups and majority students [7,11,25]. There is a lot of evidence about these teaching practices. These give rise to motivating work that stimulates creative and innovative thinking, enhances their autonomy and facilitates the learning of transversal and professional competences. In these practices, students learn by constructing new ideas or concepts based on their current and previous knowledge and are motivated to take an active role in planning their own learning [14,77].

Active learning cannot be applied if the student is not willing to work and make an effort. In this sense, prior information and clarity of objectives increase motivation and favorable expectations in relation to the activity to be carried out [43]. To achieve active learning in students, the teacher must propose activities that:
1. Support the work and the involvement of the student: It is considered vital as a prerequisite for the acquisition of new knowledge.

2. Be motivating: The teacher must know how to capture students' attention, surprise them, clarify the objectives intended for that specific activity, and be willing to offer the necessary support and help so that the student can achieve the planned goals.

3. Do not involve great efforts for the student: You can become frustrated when you see that you are not achieving your goals, but neither should they be easy to resolve.

4. Adjusted to the group itself: Propose cooperative learning activities based on the group itself as the engine and builder of knowledge.

5. They are appropriate to the objectives that have been set: They must be planned in the programming of the subject.

6. Clarify the type of activities: Keeping the student constantly informed favors development and success, as they know what is expected of them and what to do.

Both teachers and students should strive to apply the seven principles of quality teaching: Encourage contact between students and faculty, develop reciprocity and cooperation among students, encourage active learning, give prompt feedback, emphasize time on task, communicate high expectations, and respect diverse talents and ways of learning $[4,17]$. Students are not simply passive agents, as learning is not only a matter of listening in class, taking notes, and occasionally asking the teacher a question but above all of participation and commitment if the objectives established for the subject are to be met. Teachers themselves are therefore required to adopt new approaches to teaching in class, as well as a new role of guiding and facilitating the learning process.

The student must be able to respond to the different learning proposals. Each one has their own way of acquiring knowledge, and they must also know how to organize and prioritize their learning [58].

Bransford [13] and Weimar [89] argue that traditional teacher-centered teaching places students in a passive role and hinders commitment and motivation and results in superficial knowledge development [5]. Therefore, it is necessary to increase and make more frequent the innovations in the methods of instruction and the educational practices that stimulate greater participation of the students in the different learning processes.

Where active learning is concerned, teachers are not the central focus point (since they do not confine themselves to transmitting knowledge and "making" students learn), but rather it is the student who assumes the responsibility for learning. As a practical and creative 
methodology, active learning places students at the center of the learning experience to enhance motivation [73]. Active-learning methodologies bring us closer to the heart of the learning process in which teachers share the learning experiences of their students more closely, thereby making the process both richer and bolder $[64,67]$. Communicating high expectations to students in conjunction with stimulating active learning is part of the principles for a quality teaching experience. The teacher must implement meaningful learning and promote an interaction based on observation, stimulation, and curiosity, among other phenomena.

\section{1 | Thinking processes and instructional approaches}

Four teaching methodologies based on the above criteria are defined and will be applied in this study.

\subsection{1 | Flipped classroom}

It is a reverse process where students learn autonomously and review and solve doubts in the classroom. The role of the teacher becomes that of a guide who offers educational material in different formats and then clarifies the concepts that students have not understood on their own. The origin of the FC approach can be found in the work of Bergmann and Sams [8]. FC is an educational technique consisting of two parts: interactive group learning activities within the classroom (active in the classroom) and direct individual computer-based instruction outside the classroom (activities outside of the classroom) [10], although teachers cannot assume that students will see or read the main documentation before arriving at the classroom [39].

The use and implementation of FC depend largely on the type of students and subject, which can vary in preparation, scientific reasoning ability, or self-directed learning skills [69] and may, for the benefit of the teacher, lead to an eventual reduction in the workload associated with teaching preparation time [30]. FC transfers the work of certain learning processes outside the classroom and uses classroom time, together with the teacher's experience, to facilitate and enhance other knowledge acquisition and practice processes within the classroom [53]. It is a comprehensive approach that, when applied successfully, will support all phases of a learning cycle.

Akçayır [2] reports that applying the FC model in higher education improved student satisfaction by up to $18 \%$ and their level of commitment by up to $14 \%$. Other authors show favorable results where students were satisfied with the teaching method, and it was important in their learning process $[6,15]$.

\subsection{2 | Design thinking}

It is focused on giving a practical use to the learning process. The basis of this methodology is creative problem-solving, either real or imaginary. These problems have multiple solutions, which students are required to address with empathy, define, ideate, and evaluate, as well as create prototypes. Through DT, problems that are not clearly defined can be solved, obtaining information, analyzing content, and proposing design solutions [14]. It is a way of thinking that combines knowledge and understanding of the context to face creative solutions and novel solution proposals with the limits that reality imposes [32,71].

DT, first used by Herbert Simon [76], proposes a pedagogical approach to promote professional skills such as leadership and inclusion and stimulate creative development, a technical mindset, and innovation. For example, developing empathy in users and involving them in the learning process is a fundamental principle in DT and is present in many examples of the practices observed and documented in instruction designers [21,40,52]. The Hasso Plattner Design Institute at Stanford describes DT as a five-stage process (empathize, define, ideate, prototype, test). These stages are not always sequential, and designers can often run the stages in parallel, out of order, and/or repeat them iteratively. The various stages of DT should be understood as different modes that contribute to the entire design project, rather than sequential steps. The ultimate goal is to gain as deep an understanding of the product and its users as possible [16].

Studying the DT application needs more work to understand how it can be applied to the design of engineering courses and curricula, and how the unique characteristics of these environments can affect such applications. This study can help that purpose, and today, its application has been expanded to address broader problems, and the role it can play in educational settings is studied $[18,28,49]$.

\subsection{3 | Visual thinking}

It helps the student to internalize complex concepts in a simpler way. This methodology is based on the notion that every person is capable of drawing. The importance of teaching students to draw is fundamental in the 
context of graphic and design subjects; it is an important means of VT and an important process of "thinking out loud" [74]. VT, with the use of drawings, graphics, images, and animations, improves learning, and attracts interest and is a strategy that educators are using more and more effectively [57].

VT is one of the distinctive characteristics of an engineer. It is useful for documenting, representing, and reasoning ideas and designs and communicating them to others. Its importance is recognized as a means of communication and a tool for reasoning. A sketch or a quick drawing is an extension of short-term memory. Greater skill in quick drawing aids visualization, storing more information through these visualizations. It is not necessary to create a detailed sketch to effectively visualize a concept; a simple representation based on an understanding of basic shapes and perspectives is sufficient [81].

VT is defined according to the field under study. Goldschmidt [35] explains it from a design perspective as the process and reasoning behind creating ideas or shapes in design; engages teachers to provide educational opportunities for students for visual and spatial (3D) exploration, and to fully immerse themselves in individual or collaborative settings. Visualization techniques are considered an integral and important part of university education. As these techniques become increasingly useful for learning and understanding, students must be able to think visually and communicate more effectively using images $[65,87]$. VT opens up new ways to solve problems, provide alternative thinking about design and engineering, and improve problem-solving education and practice $[19,80]$.

\subsection{4 | Project-based learning}

It is recognized as a student-centered model for education. In this methodology, the student learns by building new ideas or concepts based on their current and previous knowledge and on the development of self-directed learning skills [90]. At PBL, students must gain the ability to collaboratively apply knowledge to new situations by facing open, poorly structured, or similar problems in a real-world situation. Students working at PBL should do so in teams to identify needs and solve different types of problems. They must acquire and assess their knowledge through specific projects and feel more motivated to take an active role in planning their own learning. Each student associates the concepts they acquire with other ideas they already possess and must be able to put them into practice in a specific context and with a proposed objective. The PBL approach facilitates student learning with a different style of teaching compared to traditionally accepted styles [42,55].

Karlin and Viani [48] point it out as a strategy where students plan, implement, and evaluate projects that have application in the real world beyond the classroom and in which transversal and professional competences are worked on [84].

There is abundant evidence in the literature on the effectiveness of applying PBL. PBL improves professional skills and problem-solving, teamwork is more effective, and there is more confidence, motivation, and long-term retention of knowledge and the development of deep learning $[51,88]$.

\section{2 | Study objectives}

Taking into account the didactic characteristics of this training proposal, through the development of an evidence-based active-learning approach that allows a better understanding by students, we ask ourselves the following research questions:

1. What is the effect of implementing different instructional strategies on students' achievement?

2. What is the effect of focusing on thinking processes on students' achievement?

3. To what extent instructional strategies and dealing with thinking processes improve the satisfaction of students?

This study will be useful for those teachers and researchers who want to reinforce student learning by applying different active methodologies with the aim of achieving better academic results and promoting creative and innovative thinking in students.

This study aims to fill the existing gaps in the application of active learning techniques in the practices and laboratories of subjects in the field of graphic engineering and improve the learning process in the development of teaching activities.

\section{2 | METHODOLOGY}

\section{1 | Context of the study}

In the process of adaptation to the EHEA initiated by the authors' university, innovative educational models have been incorporated into their curricula, such as training in generic or transversal competencies and new teaching/ learning methodologies. As a result of this adaptation, 
new classroom activities and ways of organizing time and teaching space have been planned and new teaching/ learning models have appeared [41,83].

This study presents an educational innovation experience where four active learning strategies (FC, DT, VT, and PBL) have been applied, in the classroom and outside it, in the compulsory subject Graphic Expression (GE). The results of this experience (which is still ongoing) are shown in this longitudinal and quantitative study that was carried out during the academic years from 2015 to 2018. Previously, the subject was taught with more traditional methods (single final evaluation, long expository theoretical classes, scarce possibility of diversifying the exercises, little interaction in the classroom, etc.).

The compulsory subject GE, which carries six ECTS credits and is imparted during the first and the second quarter to approximately 700 students per course. The class groups, 24 in total, consisted of 30 students in morning (M) or afternoon (A) sessions in all the degree courses (Electrical Engineering, Mechanics, Chemistry, Industrial Electronics, Biomedicine, Energy and Materials) at the Escola d'Enginyeria de Barcelona Est from the Universitat Politècnica de Catalunya (UPC BarcelonaTech).

The assessment of the autonomous learning generic competence is assigned to the subject GE [63] together with the specific competencies belonging to the subject. This generic competence is acquired and assessed through the execution of different activities during the application of knowledge on standardization, technical drawing, and spatial geometry. During the course, the student will learn graphic, written, and oral communication techniques; teamwork and organization, and time planning. The activities carried out (inside and outside the classroom) are diverse: theoretical learning through a self-assessment test, problem-solving with the use of solid modeling tools through computer-aided design (CAD) supported by videos, hand sketches elevation, and the elaboration of a final project in the group of an engineering set, among other activities [26]. This student-centered experience aims to boost spatial conception, deepen the knowledge of shapes, and put into practice the technical rules of graphic representation most commonly employed in engineering by means of CAD.

\section{2 | Subject structure}

These active learning experiences (FC, DT, VT, and PBL) have been implemented during 4 academic years (each year has two quarters) in the subject GE to various class groups from the first quarter of 2015 to the second quarter of 2018. Each quarter is taught from February to May and from September to December (13 sessions each quarter). In total, 11 class groups of 30 students per class (a total of 330) have participated in this experience. Students are new to the university, and their gender, ethnicity, or country of origin has not been taken into account.

These methodologies have been applied during the three teaching hours in the classroom and outside of them. In these sessions (one session is 1 week of the classroom) different activities are planned to achieve the acquisition of the objectives of the subject by the students.

The specific objectives of the subject can be seen at this link (https://tinyurl.com/ydz3egp7-Spanish language). The complete study guide for students to follow all the academic activities of the course can be seen at this link (https://tinyurl.com/y7ygwh6h-Catalan language).

Table 1 shows all active-learning activities (per week) and topics to be learned by students during an academic year, including compulsory assessments.

\section{3 | Data collection and analysis}

The methodological approach developed in this study is based on the use of instruments to collect and analyze the marks obtained using the different active methodologies described in this manuscript. Finally, a survey is carried out to obtain the opinion of the students on the satisfaction of their application. The following sections describe the collection of information for each of these methodologies.

Assessment of the subject consisted of seven preestablished tests set on weeks 5, 9, 10, and 13 of the quarter. Two of these tests were theoretical (TTN and TTG), three practical (CAD1, CAD2, and CAD3), one based on spatial skills (PCA [Mid-term sketching and adjustments]) and final delivery of the group project (Proj).

These activities were conducted through active methodologies and accounted for $100 \%$ of the total evaluation of the subject.

The final mark for the subject was calculated according to the following formula:

$$
\begin{aligned}
\text { Final mark }= & 0.1 \times \mathrm{CAD} 1+0.25 \times \mathrm{CAD} 2 \\
& +0.15 \times \mathrm{CAD} 3+0.1 \times \mathrm{PCA} \\
& +0.15 \times \mathrm{TTN}+0.1 \times \mathrm{TTG}+0.15 \times \text { Proj }
\end{aligned}
$$

where 


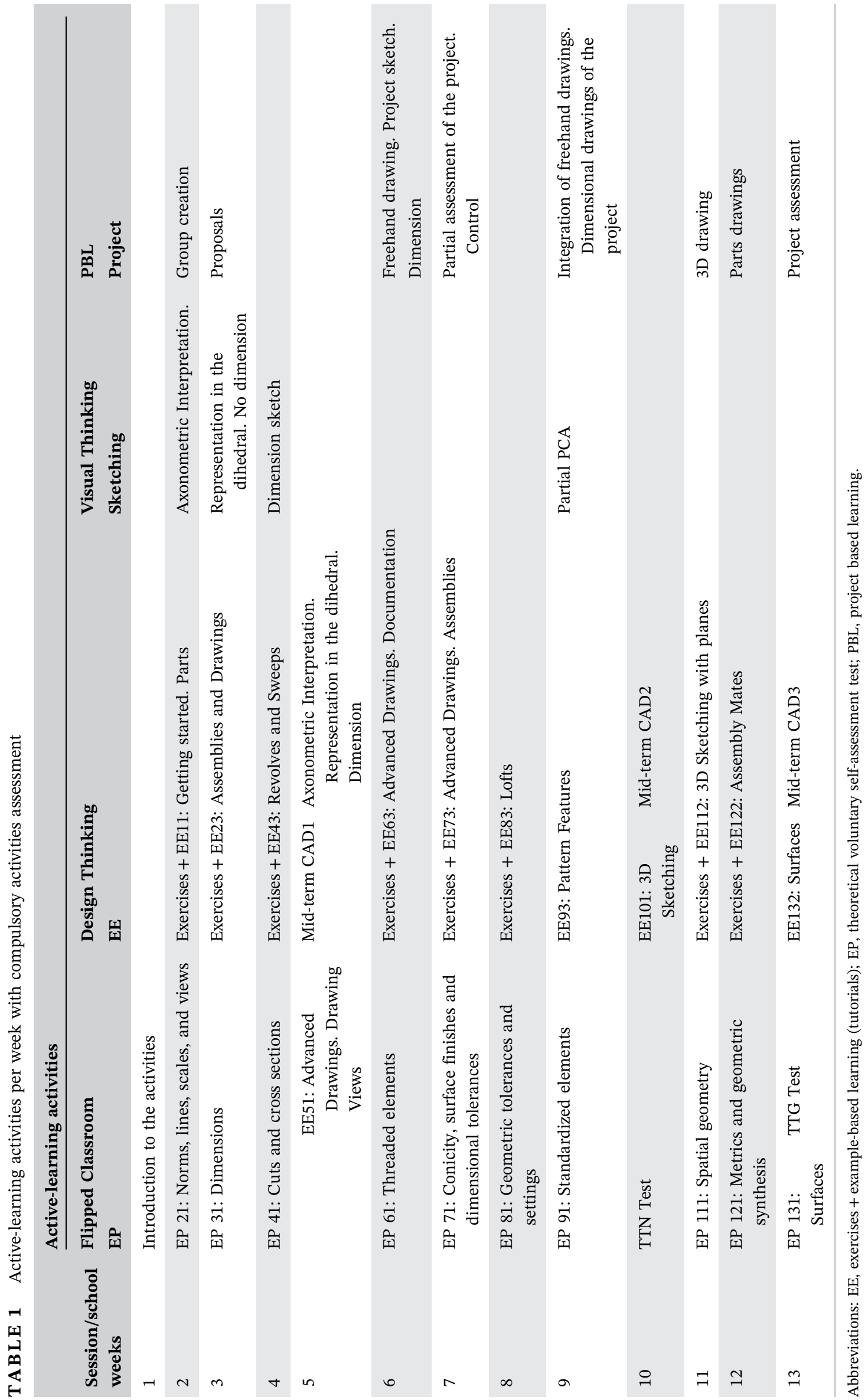




\begin{tabular}{|c|c|c|}
\hline $\begin{array}{l}\text { Evaluation } \\
\text { tests of theory } \\
\text { in class }\end{array}$ & $\begin{array}{l}\text { Evaluation tests of } \\
\text { problems in class }\end{array}$ & Proj: \\
\hline $\begin{array}{l}\text { TTN = Drawing } \\
\text { norms self- } \\
\text { assessment } \\
\text { test }\end{array}$ & $\begin{array}{c}\text { CAD1 = 1st mid-term } \\
\text { exam. Making of } \\
\text { parts and drawing }\end{array}$ & $\begin{array}{c}\text { Final group } \\
\text { project }\end{array}$ \\
\hline $\begin{array}{l}\text { TTG = Self- } \\
\text { assessment } \\
\text { spatial } \\
\text { geometry test }\end{array}$ & $\begin{array}{l}\text { CAD2 = 2nd mid-term } \\
\text { exam. Making of } \\
\text { parts, drawing, and } \\
\text { assembly of parts }\end{array}$ & $\begin{array}{l}\text { Distance } \\
\text { learning }\end{array}$ \\
\hline $\begin{array}{c}\text { PCA = Mid-term } \\
\text { sketching and } \\
\text { adjustments }\end{array}$ & $\begin{array}{l}\text { CAD3 }=\text { 3rd partial } \\
\text { exam. Spatial } \\
\text { geometry }\end{array}$ & \\
\hline
\end{tabular}

\subsection{Application of the FC methodology}

The FC methodology is applied to self-learning activities of theoretical content outside of class time. Before the session, the students can consult the documentation that the teaching staff has available on the virtual campus Atenea from UPC BarcelonaTech. This documentation is related to the specific objectives associated with the following session and is closely linked to solving the problems raised in the previous session. Table 2 shows some of the topics (and their description) to be studied, the specific competence that is acquired, and where to find the topic of the recommended bibliography.

Figure 1 shows part of the consultation documentation and self-study material that students have available on the virtual campus Atenea from UPC BarcelonaTech.

To check that the objectives set for the theoretical content had been met and also to encourage individual responsibility during the self-learning process, students were presented with a multiple-choice, self-assessment test on the virtual classroom to be completed voluntarily outside of class hours.

These consisted of a total of 10 assessment tests associated with 10 classroom sessions. Only two attempts of $10 \mathrm{~min}$, with a delay of $30 \mathrm{~min}$ between attempts, were required to complete this test. Each test-type consisted of six questions chosen at random from a question bank, with four responses also ordered at random. On completion of the test, the system provided information on the final marks obtained, but not about the correct answer to each question. These tests were simply created for the students since they were required to find on their own initiative the correct answers in the bibliography provided or to seek consultation with the teacher.

Doubts were resolved, and concepts regarding the standardization of engineering drawings were reviewed during class sessions (using the resources available on the virtual campus and with explanations by the teacher) to facilitate the solution of the problems posed.

Figure 2 shows an example of some of the questions on the self-assessment test.

Finally, the evidence (for the final grade for the course) is obtained from the compulsory assessment activities carried out in sessions 10 (TTN) and 13 (TTG).

\subsection{Application of the DT methodology}

The DT methodology is applied in the classroom and outside it. In classroom was applied by the completion of two or three exercises per session using the Solidworks Education Edition $2017^{\circledR}$ CAD tool, which enables a three-dimensional mathematical model to be created by moving from a drawn object to a constructed object and vice versa. This methodology is closely related to the PBL methodology. Each one of the exercises carried out in this

TABLE 2 Specific objectives associated with a session

\begin{tabular}{|c|c|c|c|}
\hline Subject & Competence & Description & Bibliography \\
\hline Normative concepts & Knowledge & $\begin{array}{l}\text { Define objectives of standardization } \\
\text { Enumerate most important standardization entities }\end{array}$ & Page $1-5$ \\
\hline Normative formats & & $\begin{array}{l}\text { Enumerate basic standardized formats } \\
\text { Describe the relation between basic standardized formats } \\
\text { Enumerate worksheet } \\
\text { Enumerate compulsory elements of a title block } \\
\text { Enumerate complementary elements of a title block }\end{array}$ & Page $6-10$ \\
\hline Normative scales & & $\begin{array}{l}\text { Define the concept of scale } \\
\text { Enumerate the basic standardized scales }\end{array}$ & Page 11-12 \\
\hline Normative views & & $\begin{array}{l}\text { Enumerate general rules of view selection } \\
\text { Enumerate all the main views in orthographic projection }\end{array}$ & $\begin{array}{l}\text { Page } 13 \\
\text { Page 14-19 }\end{array}$ \\
\hline
\end{tabular}




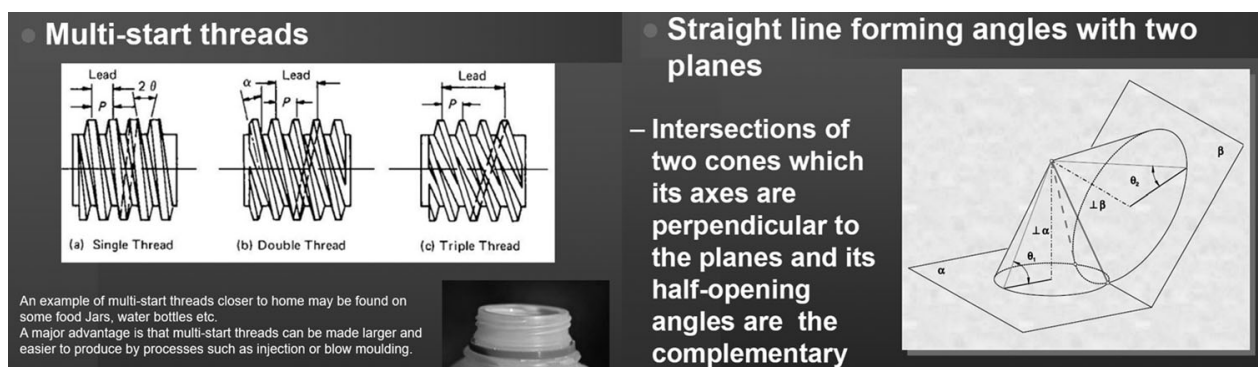

FI G URE 1 Self-study material

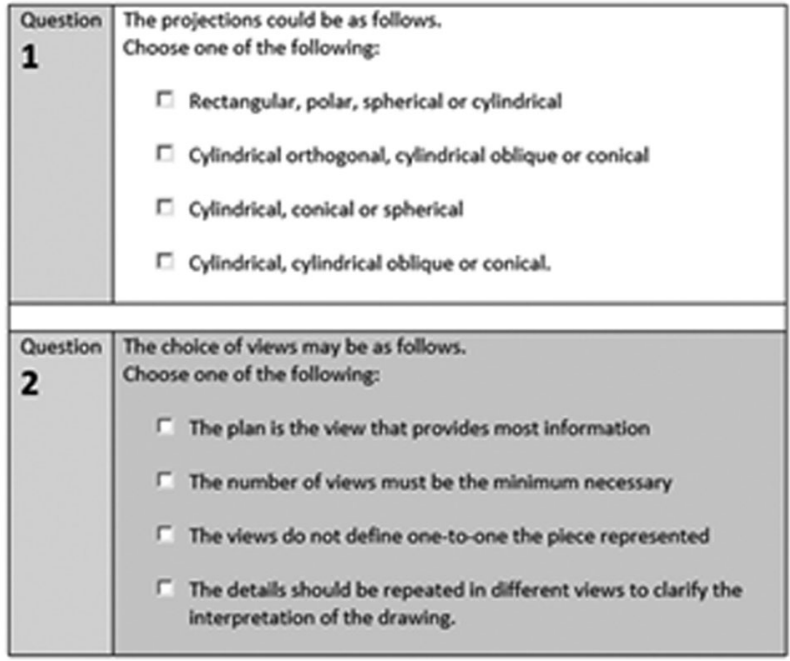

FIG URE 2 Example of an assessment test stage will be of great importance to understand and carry out the project that the students must deliver at the end of the course. During the first three class sessions, the student is instructed on the five stages (Empathize, Define, Ideate, Prototype, and Test) that must be followed to apply this methodology.

Figure $3 \mathrm{a}$ is a proposed exercise that shows the different views of the planes (Dihedral) and Figure 3b shows the view of the part (Axonometric).

Table 3 provides a summary of the objectives and a description of the sessions when using this methodology.

These exercises were to be completed in each session, either individually or in groups of between two and three students, depending on their complexity. During these sessions, students were responsible for their own individual tasks, while the teacher, on the other hand, had to resolve
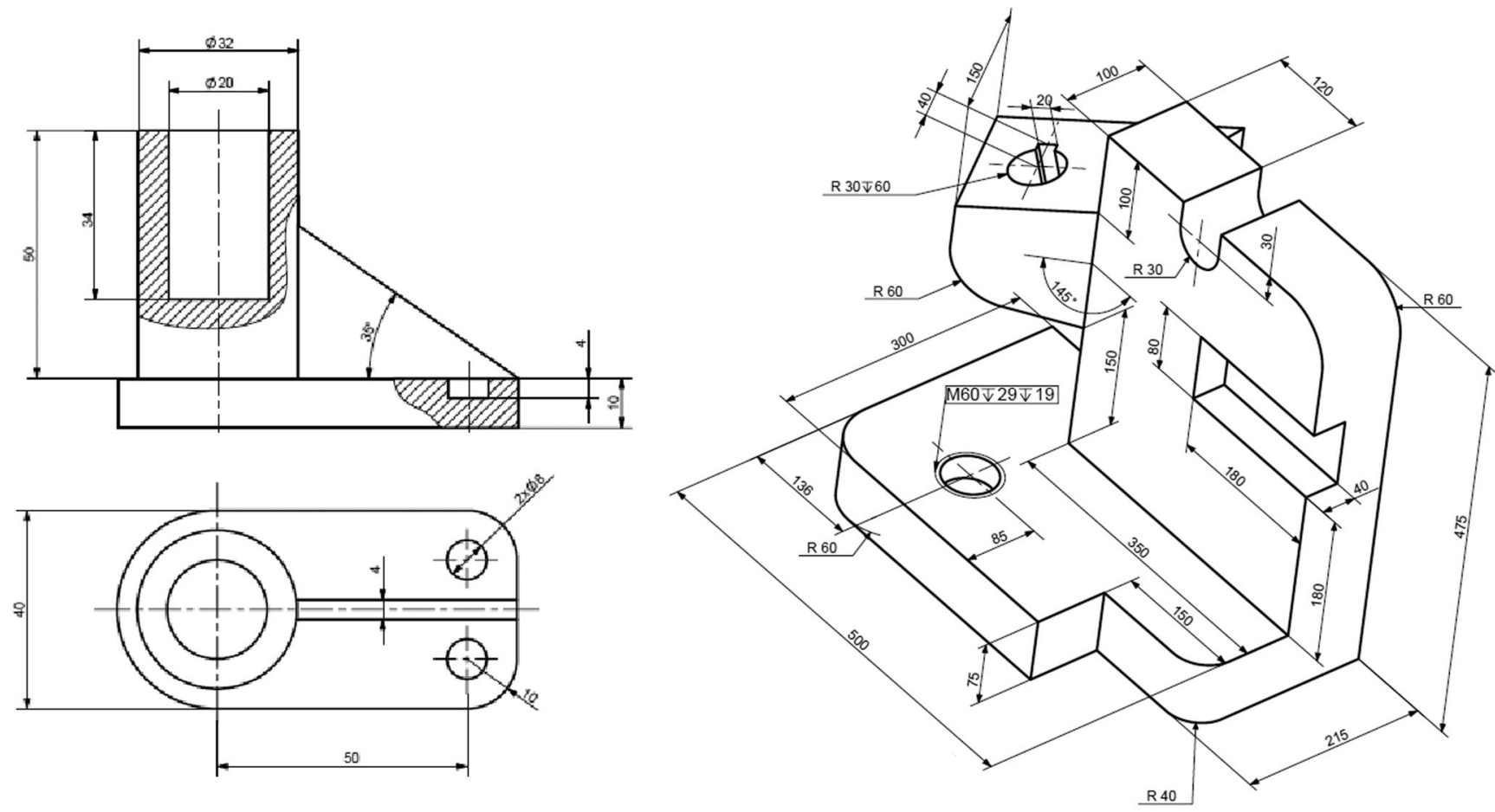

FIG URE 3 (a) Dihedral. (b) Axonometric 
TABLE 3 Objectives and description of the sessions using the Design Thinking methodology

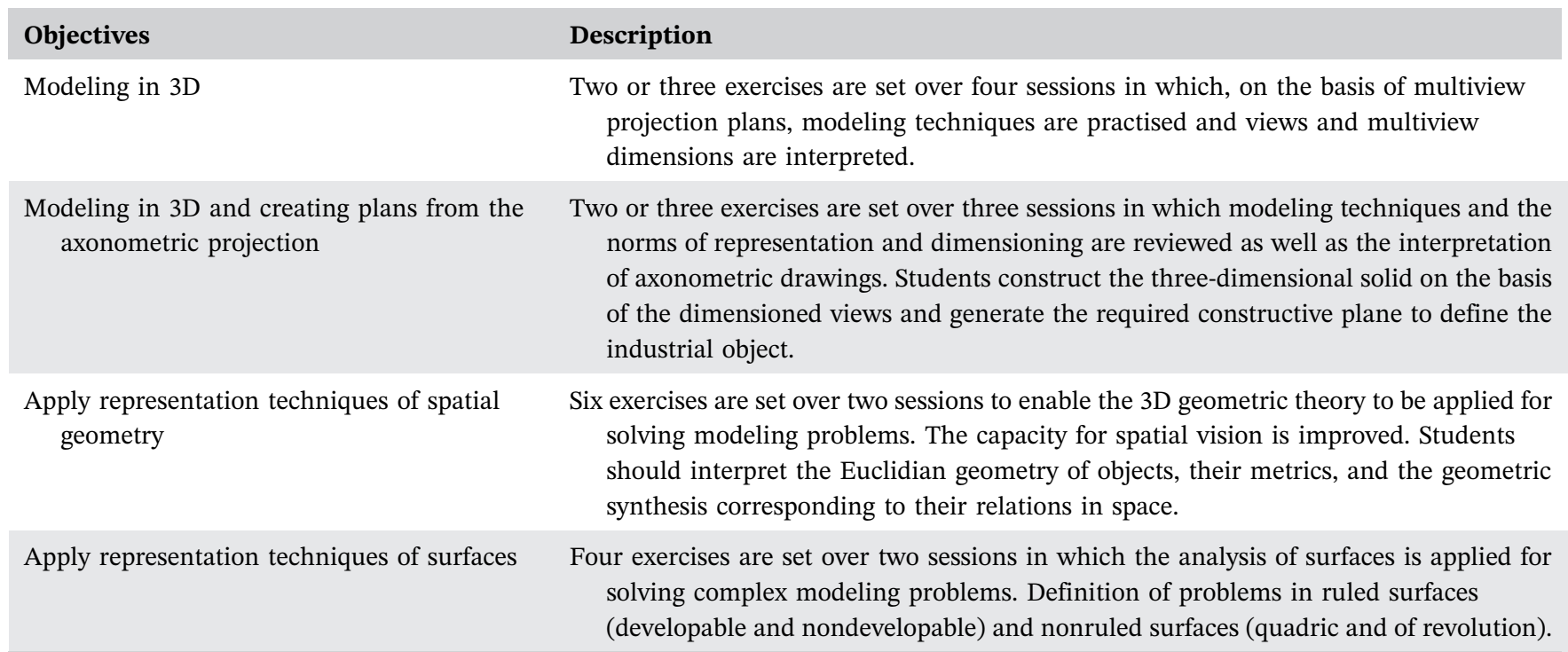

any doubts and to propose group discussions to guide students through the exercises, thereby facilitating immediate and individualized feedback. If the tasks were not completed in the classroom, the students were required to finish them and hand them in within a week. To facilitate this task, the student has at his disposal the solution of each exercise in video format, but the teacher only recommends viewing it when it is not possible to find the solution.

During the first two sessions, students who were observed to be less skillful in the use of solid modeling tools were asked to complete additional exercises outside of class time, thus making the teaching-learning process significantly individualized. The level of complexity of the exercises was increased throughout the course.

For the application of the DT methodology outside the classroom and as a complement to the face-to-face activities (to improve in the practice of performing pieces), outside of classroom time and individually, students are given a support material with 12 tutorials. With this material, students will find it easier to develop a consistent design, simulation, analysis, and presentation techniques. The teacher recommends doing one tutorial per week and that it be sent through the virtual campus Atenea for subsequent correction. Some practical topics in the classroom are only explained in these tutorials, so it is recommended that they be carried out and delivered on time and are essential for the successful completion of the group project that they are required to present at the end of the course. Figure 4 shows the 12 tutorials to be performed.

Finally, the evidence (for the final mark for the course) is obtained from the compulsory assessment activities carried out in sessions 5 (CAD1), 10 (CAD2), and 13 (CAD3). The correction of the midterm exams is done through the rubrics that can be seen at these links (CAD1, https:// tinyurl.com/ybpguplw and CAD2, https:/tinyurl.com/ y8p74ffm-in the Spanish language). CAD3 lacks rubrics.

\section{6 | Application of the VT methodology}

The VT methodology was applied to the development of skills for the recognition and production of visual images.
EE11. Getting started. Parts.
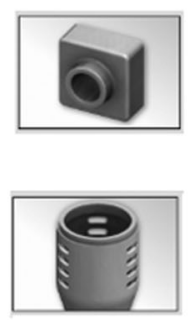

EE93. Pattern Features.
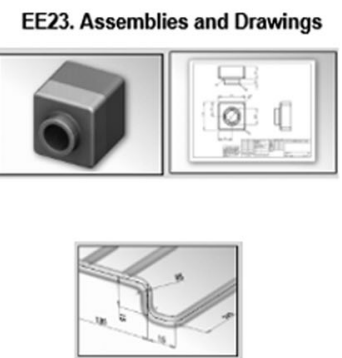

EE101. 3D Sketching.
EE43. Revolves and Sweeps.
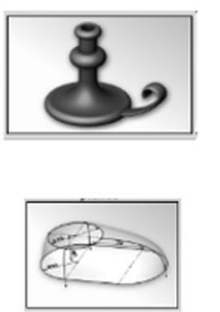

EE112. 3D Sketching with planes.

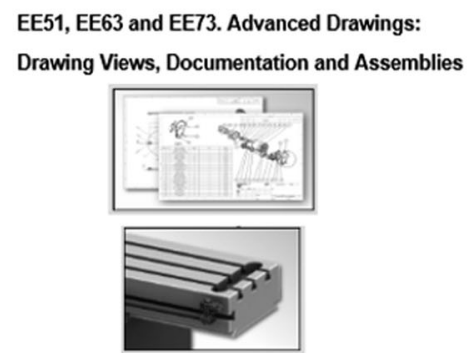

EE122. Assembly Mates.
EE83. Lofts.
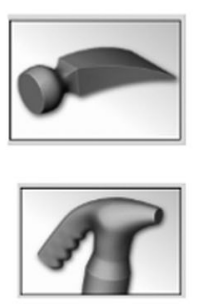

EE132. Surfaces.

FI G URE 4 Support material of 12 tutorials 
For this, techniques are used that allow axonometric interpretation and representation in a bounded and unbounded dihedral.

This methodology makes complex ideas more accessible and enables them to be summarized in the form of principle ideas. The activities associated with this methodology require an individual involvement, although it is highly useful to conduct guided correction in groups, which helps students to place themselves in a 3D space, envisage mental maps of the location of the three planes (elevation, plan, and section) and make projections of each one.

As a resource for assisting with this methodology, students had at their disposal a freehand sketchbook and rough drafts in which they had to complete a series of 20 exercises, individually and outside of class time, over the first eight sessions using paper and pencil. Table 4 summarizes these activities. In Table 1 we can see this in formation supplemented and related to the rest of the activities.

Two examples of these exercises can be seen in Figure 5.

Finally, the evidence (for the final mark for the course) is obtained from the compulsory assessment activity carried out in session 9 (PCA). The rubric with which this evidence is evaluated can be seen at this link (https://tinyurl.com/y9qkajln—in the Spanish language).

\section{7 | Application of the PBL methodology}

The PBL methodology was applied in the completion and delivery of an original engineering project consisting of a set of different mechanical components undertaken by a group of between three and four students.

The students undertook the project under the supervision of a teacher and delivered it at the end of the course with a public presentation and defense. The project content had to include a brief report, freehand drawings of the parts, printed plans with multiview projections of each part, exploded views with each part identified, specific movements of the set, assemblages, and a video presentation of the project.

During the first class sessions, the teacher spends time introducing the five stages related to DT methodology (closely linked to carrying out the project). These stages are:

Stage 1. Empathize: Gain an empathetic understanding of the problem you are trying to solve.

Stage 2. Define: Indicate the needs and problems. Accumulate the information you created and collected during the Empathize stage.

Stage 3. Ideate: Generate ideas. Find alternative ways to view the problem and identify innovative solutions to the problem that has been created.

Stage 4. Prototype: start creating solutions. Identify the best possible solution for each of the problems identified during the first three stages.

Stage 5. Test: The complete engineering set is rigorously tested using the best solutions identified in the prototype phase.

Approximately every 2 weeks, the teacher devoted the last half-an-hour of the session to monitor the progress of the project, during which the components of the different groups were brought together, doubts were addressed, and a debate held on the possible solutions of the project. Half-way through the course, an advanced delivery of the project was made and was then returned with pertinent feedback. Table 5 shows the chronology of the different sessions and the activities carried out as a complement to Table 1.

For the final mark of the subject, this evidence is obtained with the evaluation rubric that can be seen at this link (https://tinyurl.com/yd5z2hbu—Catalan language).

\subsection{Summary of methodologies}

Finally, Table 6 shows a summary of the application of the different learning methodologies both in the classroom and outside it. The relationship with the proposed learning objectives, the activities to be carried out, the scope, the place where these activities are carried out, the

\begin{tabular}{|c|c|c|}
\hline Session & Sketching exercises & Activity \\
\hline S2-S3 & 1 to 6 & Axonometric interpretation \\
\hline & & Representation in the dihedral. No dimension \\
\hline S4 & & $\begin{array}{l}\text { Sketching exercises. Dimensioning of sketches } \\
\text { made in previous sessions }\end{array}$ \\
\hline S5-S6-S7-S8 & 7 to 20 & $\begin{array}{l}\text { Axonometric interpretation and representation in } \\
\text { the dihedral. Dimension }\end{array}$ \\
\hline
\end{tabular}

TABLE 4 Activities related to sessions and sketching exercises 

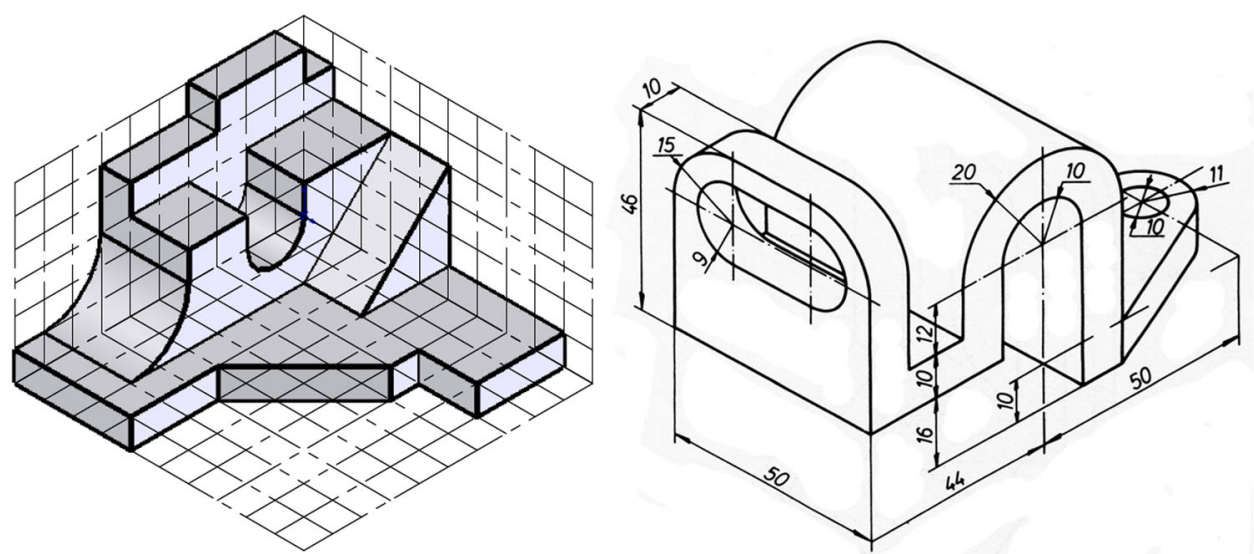

FI G URE 5 Examples of sketching exercises

resources available to the students, the expected feedback, as well as the different evidence and evaluation are shown (According to the formula of the final mark).

\section{9 | Student satisfaction survey}

Finally, to determine the opinion of the students on their satisfaction with the subject and the application of the different active learning experiences, among other variables, at the end of the academic year, an anonymous statistical-descriptive online survey was conducted using Google Forms ${ }^{\circledR}$.

TABLE 5 Activities related to sessions and project delivery
This survey is a necessary process to obtain information from a population by asking questions of a representative sample. The information is collected in a structured way by asking the same questions and in the same order to each of the respondents.

The survey that was sent is of type Students' Evaluation of Educational Quality (SEEQ). It is a highly effective instrument for the evaluation of teaching where the data collected serves to improve the process (formative evaluation) and accredit its quality (summative evaluation) and revolves around those aspects that are considered more related to the experiences of applied learning $[54,56,70]$.

and project delivery

(1)

\begin{tabular}{|c|c|}
\hline Session & Activity \\
\hline $\mathrm{S} 2$ & $\begin{array}{l}\text { Three-people group is created for the project. } \\
\text { The project will consist of a report, plans of each piece, a global plan, a } \\
\text { PowerPoint presentation for the defense, and submission of all the files } \\
\text { implied. }\end{array}$ \\
\hline S3 & $\begin{array}{l}\text { Project group meeting (besides the individual work) to write the "Project } \\
\text { proposal." The proposal will consist of the name of the group, members, } \\
\text { theme, interest of the group on the chosen theme, sketches or photos of } \\
\text { the whole to reproduce or design, and a working plan with the } \\
\text { distribution among the members of the group. Drawings can be } \\
\text { freehanded and scanned. }\end{array}$ \\
\hline S6 & Submission of dimensioned freehand sketches of the project. \\
\hline S7 & Partial assessment of the project. \\
\hline S9 & $\begin{array}{l}\text { Integration of the dimensioned freehand sketches to the project. } \\
\text { The learned norms must be implemented in the sketches. }\end{array}$ \\
\hline S11 & 3D drawing of the pieces. \\
\hline $\mathrm{S} 12$ & Plans of the pieces of the assembly. \\
\hline S13 & $\begin{array}{l}\text { Submission of the report, the plans of the pieces of the assembly, and set up } \\
\text { of the assembly. }\end{array}$ \\
\hline
\end{tabular}




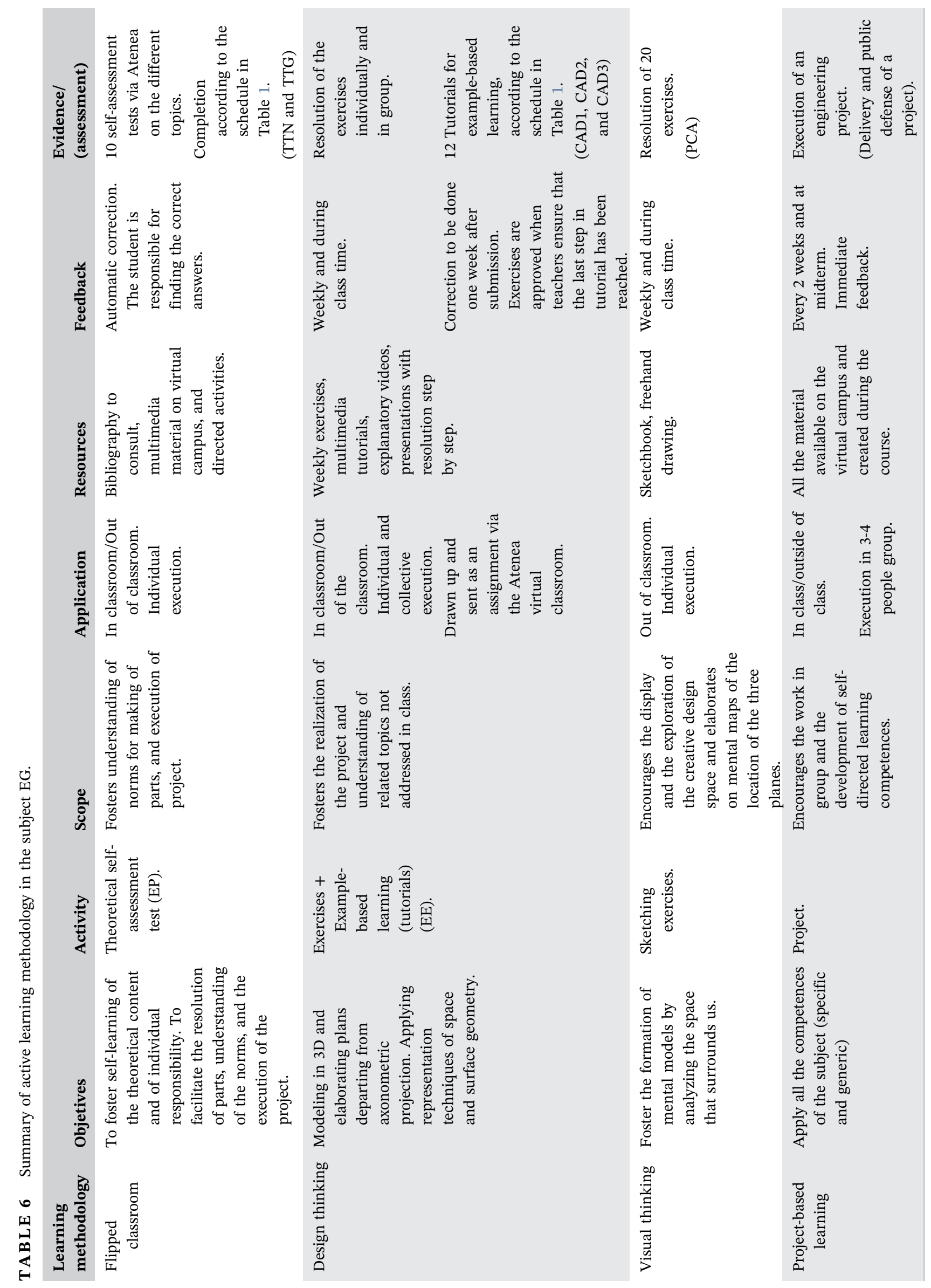


T A B LE 7 Most important design aspects of the survey

\begin{tabular}{|l|l|}
\hline Survey & $\begin{array}{l}\text { Description } \\
\text { Descriptive statistical } \\
\text { Nonprobability sampling by judgment } \\
\text { or opinion }\end{array}$ \\
\hline Population & $\begin{array}{l}\text { One-year students of the subject EG at } \\
\text { Escola d'Enginyeria de } \\
\text { Barcelona Est }\end{array}$ \\
\hline Confidence interval & $95 \%$ \\
\hline Sampling error & 0, 02\% \\
\hline Standard deviation & See Table 14 \\
\hline Survey period & 2015 to 2018 \\
\hline Sample & 330 students (answers 271, 82\%) \\
\hline Process & Survey anonymous online \\
\hline Type of survey & SEEQ \\
\hline Data collection & Google Forms \\
\hline instruments & \\
\hline Data analysis & IBM SPSS v19 Solutions for Education ${ }^{\circledR}$ \\
\hline instruments & \\
\hline
\end{tabular}

Abbreviation: SEEQ, Students' Evaluation of Educational Quality.

The objective of the survey (and that is part of this study) was to verify if the active-learning methodologies used and the incorporation of essential teaching practices have facilitated the acquisition of the objectives of the subject GE through the analysis of the perception of the students. The data collected will serve to improve the strategies implemented in the applied active-learning experiences [85]. Table 7 shows the most important design aspects of the survey.

Those aspects that are believed to be most related to learning are extracted from the survey, such as face-toface and non-face-to-face training activities, work sessions and project groups, course content and material, and workload and agility.

Students had to choose between Strongly agree (4), Agree (3), Disagree (2), and Strongly disagree (1), in the penultimate question between Very large (5), Large (4), Normal (3), Small (2). and Very small (1) and in the last one between Very fast (5), Fast (4), Normal (3), Slow (2), and Very slow (1).

Table 8 shows a summary of the aspects considered to be the most closely related to the active-learning activities applied, together with the list of questions.

The survey, which was answered voluntarily, was carried out on the last day of class (session 13) to all the students in the groups where the experience was carried out. That is, from the first quarter of 2015 to the second quarter of 2018. In total, 11 class groups of 30 students per class (a total of 330). The results obtained were processed using the IBM SPSS v19 Solutions for Education ${ }^{\circledR}$ statistical program, where the obtained variables were analyzed using descriptive statistical frequencies to determine the percentages of use of the variables.

\section{3 | RESULTS}

\section{1 | Effect of implementing the FC model on students' performance}

First, the results of the application of the FC methodology are analyzed. Table 9 shows a summary of student participation in self-learning tests, along with the percentage of students who pass the subject during the years 2015 to 2018 by quarter.

Table 9 shows that, over the 4 years of the study, the percentage of students who passed between 0 and 3 tests did not exceed $67 \%$. On the other hand, among the students who took between 4 and 6 tests, practically $100 \%$ passed the subject, which implies a great interest in learning. These data are very similar to those of the students who carried out a greater number of tests. So, it can be concluded that the voluntary completion of these tests facilitates learning.

The multiple-choice self-assessment test in the virtual classroom encouraged individual responsibility and a high degree of student engagement during the selflearning process. To a large extent, it is observed that they completed them voluntarily outside class hours and were asked (if necessary) to seek the correct answers on their own initiative in the bibliography provided or to seek consultation with the teacher.

\section{2 | Effect of implementing DT approach on students' performance}

Regarding the application of the DT methodology, with the increasing complexity of the exercises planned in and out of the classroom, together with the study of the theoretical contents, students are able to incorporate the learning objectives in a continuous and more effective way.

The first sessions are devoted to making simple pieces and plans. In the middle of the course, the students must be able to assemble, move, and rotate different pieces, and at the end of the 13 sessions, they must be able to create complex surface revolution models.

The results of applying the DT methodology can be seen in Figure 6, which reflects the complexity of the evaluable work with CAD carried out by the students. 


\begin{tabular}{ll} 
Related aspects & SEEQ survey questions \\
\hline $\begin{array}{l}\text { Face-to-face and } \\
\text { distance learning } \\
\text { activities }\end{array}$ & $\begin{array}{l}\text { Evaluate the use of the following learning activities: } \\
\text { Tutorials } \\
\text { Test } \\
\text { Sketch } \\
\text { Project } \\
\text { I tried, in general, to complete the assigned distance-based } \\
\text { activities (tutorials, tests, etc.). } \\
\text { I have participated actively in group work sessions. } \\
\text { The work groups are a good means of learning about the } \\
\text { subject and sharing ideas and knowledge. } \\
\text { The application project is very useful for a better } \\
\text { understanding of the course as well as for learning to } \\
\text { organize an assignment and finding practical } \\
\text { applications. }\end{array}$ \\
$\begin{array}{l}\text { I have learned and understood the contents } \\
\text { The bibliography, additional material, assignments, and so } \\
\text { forth, contribute to improving the evaluation and } \\
\text { understanding of the subject. }\end{array}$ \\
\hline materials \\
The workload of this course compared to others has been \\
The course has been
\end{tabular}

TABLE 8 SEEQ survey questions
The results for learning the subject that is most closely related to this methodology would be theoretical assessment tests completed outside of class time (see Table 1 , TTN $=$ drawing norms self-assessment test and TTG $=$ self-assessment spatial geometry test).

Table 10 shows the average marks of the three CAD partial exams during the years 2015 to 2018.

An increase in the average of marks over the years is appreciated. This is due, in part, to the fact that the application of this methodology in the classroom matures throughout the academic years, and the teacher finds more tools and experience to make its application more precise.

It is highlighted that the average of marks in the CAD2 mid-term exam is slightly higher. It can be seen that the student has a greater motivation to pass due to the weight of this mark in the final mark (25\%).

\section{3 | Effect of implementing VT approach on students' performance}

The exercises planned for the VT experience help in the development of skills for the recognition and production of visual images. One of the goals of this subject is for students to place themselves in a 3D space to conceive of mental maps for the location of the three planes (elevation, plan, and section), and to execute the projections of each plane. The evidence that the students have understood these exercises is appreciated with the high final marks of this partial exam (Table 11) and in the delivery of the project. Each of the pieces that make up the project, which is delivered at the end of the course, must be sketched first. The correct sketching will help build the pieces and finally assemble each of the parts.

Figure 7 shows a PCA exam model that students must perform (Figure 7a), and the final result (Figure $7 \mathrm{~b}$ ) where the evidence of its correct application is observed and the complexity of the results obtained when applying this methodology is appreciated.

\section{4 | Effect of implementing PBL approach on students' performance}

The projects undertaken by the students are of a high level and great complexity, which shows that the application of PBL yields results. The choice of the original engineering project is made according to a consensus of the individual contributions made by the members of each group of students.

One may observe in Figure $8 \mathrm{a}-\mathrm{c}$ different projects presented during the second quarter of 2107. In general, they are complex mechanisms consisting of a number of components where the different parts should include movements in harmony with all the components.

The interaction and correct movement of all the components, plans, and assemblages will be taken into 
TABLE 9 Participation of the students in the realization of the tests (average of 4 years)

\begin{tabular}{|c|c|c|c|c|c|c|c|c|c|c|c|c|c|c|c|c|}
\hline \multirow[b]{3}{*}{ Test completed } & \multicolumn{16}{|c|}{ Year/Quarter } \\
\hline & \multicolumn{2}{|c|}{2015} & \multicolumn{2}{|c|}{2016} & \multicolumn{2}{|c|}{2017} & \multicolumn{2}{|c|}{2018} & \multicolumn{2}{|c|}{2015} & \multicolumn{2}{|c|}{2016} & \multicolumn{2}{|c|}{2017} & \multicolumn{2}{|c|}{2018} \\
\hline & $1 Q$ & $2 Q$ & 1Q & $2 Q$ & 1Q & $2 Q$ & 1Q & $2 Q$ & $1 Q$ & $2 Q$ & 1Q & $2 Q$ & 1Q & $2 Q$ & $1 Q$ & $2 Q$ \\
\hline $0-3$ & 18 & 19 & 21 & 23 & 21 & 20 & 22 & 23 & 57 & 62 & 67 & 63 & 60 & 66 & 63 & 65 \\
\hline $7-9$ & 65 & 67 & 68 & 72 & 68 & 67 & 70 & 65 & 95 & 96 & 98 & 98 & 100 & 96 & 97 & 96 \\
\hline
\end{tabular}

account for the assessment of the project. The assessment is conducted by means of a rubric in which all the parts of the project are marked in the same way. Furthermore, the animation of mechanisms and the making of a video for the defense of the project are assessed positively and will be reflected in the final mark. This provides an incentive for the groups to make the best presentation possible.

Table 12 shows the parts of the project and the criteria that the group must take into account when presenting the project.

\section{5 | Overall effect of implemented instructional design on learners' achievement}

As previously mentioned (in the context of the study), before 2015 this subject was taught with more traditional methods (single final evaluation, long theoretical lectures, little possibility of diversifying the exercises, little interaction in the classroom, etc.). The teachers observed that the expository classes were not effective, and the performance and motivation necessary to achieve the desired learning objectives were not achieved. Starting in 2015, these learning methodologies begin to be applied in the classroom, making face-to-face and non-face-to-face classes more effective.
TABLE 10 Average marks of the CAD midterm exams during the years 2015 to 2018

\begin{tabular}{|c|c|c|c|c|c|c|c|c|}
\hline \multirow[b]{3}{*}{ Partial CAD } & \multicolumn{8}{|c|}{ Year/quarter } \\
\hline & \multicolumn{2}{|l|}{2015} & \multicolumn{2}{|l|}{2016} & \multicolumn{2}{|l|}{2017} & \multicolumn{2}{|l|}{2018} \\
\hline & $1 Q$ & $2 Q$ & $1 Q$ & $2 Q$ & $1 Q$ & $2 Q$ & $1 Q$ & $2 Q$ \\
\hline $\begin{array}{c}\text { Average mark } \\
\text { CAD } 1\end{array}$ & 5,21 & 6,83 & 5,25 & 5,48 & 7,61 & 6,07 & 6,61 & 7,16 \\
\hline $\begin{array}{l}\text { Average mark } \\
\text { CAD } 2\end{array}$ & 6,29 & 6,64 & 6,41 & 6,48 & 6,09 & 6,65 & 6,49 & 6,91 \\
\hline $\begin{array}{l}\text { Average mark } \\
\text { CAD } 3\end{array}$ & 5,17 & 5,09 & 5,25 & 5,67 & 5,62 & 5,32 & 5,64 & 5,79 \\
\hline
\end{tabular}

Abbreviation: CAD, computer aided design.

To globally visualize and compare the success in the application of these methodologies and compare them with those obtained by the students in the period before their application, Table 13 shows the averages of the final marks for the course and the averages of the marks of the projects carried out by all the groups studied during 20152018. In addition, the marks of the single final evaluation between the years 2011 to 2014 between the different groups under study (M and $\mathrm{A}$ ) are displayed.

It can be seen that the marks obtained in the group project are generally higher than the final marks, which shows that it is the activity in which they work hardest because it is the one that motivates them the most.
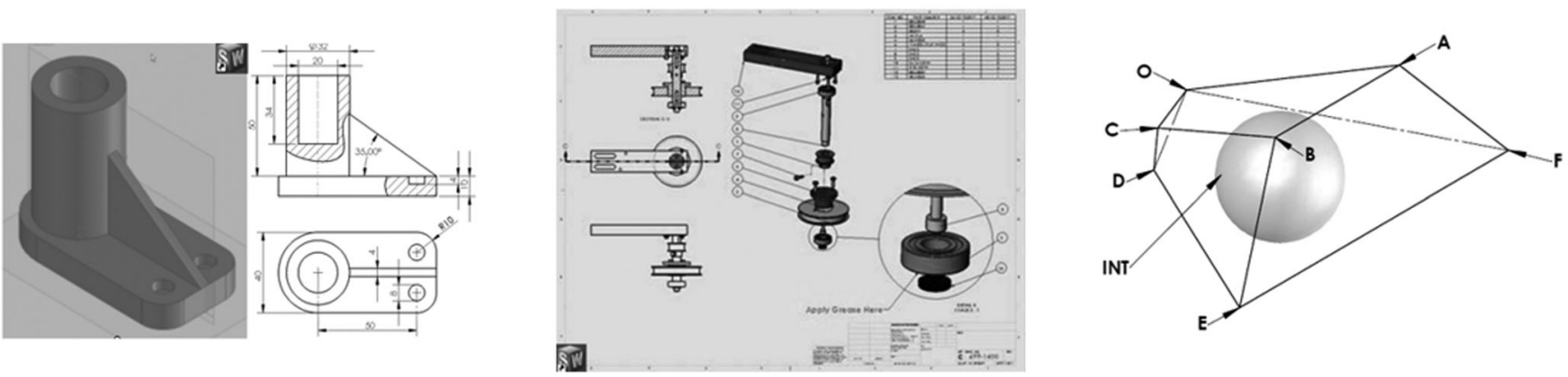

FI G U RE 6 Increasing complexity of activities with computer aided design 
TABLE 11 Average marks of the PCA partial exams during the years 2015 to 2018

\begin{tabular}{|c|c|c|c|c|c|c|c|c|}
\hline \multirow[b]{3}{*}{ Partial PCA } & \multicolumn{8}{|c|}{ Year/quarter } \\
\hline & \multicolumn{2}{|c|}{2015} & \multicolumn{2}{|c|}{2016} & \multicolumn{2}{|c|}{2017} & \multicolumn{2}{|c|}{2018} \\
\hline & 1Q & $2 Q$ & 1Q & $2 Q$ & $1 Q$ & $2 Q$ & $1 Q$ & $2 Q$ \\
\hline Average mark PCA & 7,2 & 7 & 6,9 & 7,5 & 7,2 & 7 & 7,6 & 7,7 \\
\hline
\end{tabular}

Abbreviation: PCA, Mid-term sketching and adjustments

It can be seen (Figure 9) that the average of the final marks follows a slight upward trend throughout the years. This graph compares the marks from 2015 to 2018 with those of the 4 years before the application of these methodologies. From 2011 to 2014 the project was not part of the evaluation of the subject (no mark).

\section{6 | Student satisfaction survey results}

The survey was answered by 271 students ( $82 \%$ of the total number of students). Table 14 shows the different questions of the SEEQ survey, the weighted averages (out of 5), and the standard deviations.

The results of the survey carried out in those 4 years show that the students highly value the usefulness of the active-learning methodologies used during the course. When asked about the usefulness of carrying out the project (PBL), the trend of those who declare that it is "Very useful" is increasing throughout the 4 years in which the survey was carried out. It grows from 32\% in the first quarter of 2015 to $38 \%$ in the second quarter of 2018 . Figure 10 shows the growing trend of students very satisfied with the completion of the project.

(a)

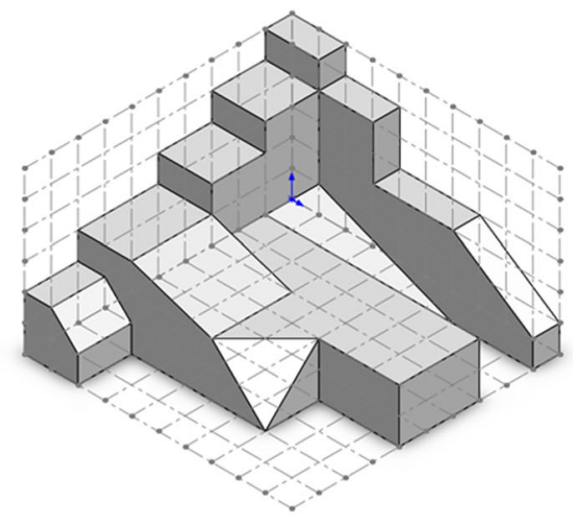

F I G URE 7 PCA examination model (midterm sketching)
When asked about the usefulness in carrying out the tutorials, in the first quarter of 2015, 76\% answered that it was between "Useful" and "Very useful." This percentage rose to $81 \%$ in the second quarter of 2018. Figure 11 shows the trend in the utility of this activity. Among those who think that it is not useful, a constant decrease is observed over the years.

However, some students do not quite see the usefulness in completing tests for self-learning of the theory in the FC strategy (41\% say that it is "Not useful." compared to $59 \%$ who say that it is between "Useful" and "Very useful"). Figure 12a shows a summary of the results for the 4 years.

Similarly, in the global of the 4 years, when asked if they have tried to carry out noncontact activities, such as tutorials, tests, or exercises outside of class time, $54 \%$ are between "Agree" and "Strongly agree" in which they have attempted to perform them. It is surprising that $41 \%$ disagree with this question, which implies that a high percentage of the students do not carry out these extra activities (Figure 12b).

When asked about their active participation in project groups, a high percentage of students thought that they had actively participated. Figure 13 shows the increasing participation, where the responses of "Strongly Agree" grow from 2015 to 2018.

Among other issues, Figure 14 shows how the students "Agree" and "Strongly Agree" that project groups are a good way to learn and share ideas and knowledge.

It was also asked if the project was very useful for understanding the course. Figure 15 shows how students responded to this question by stating that $40 \%$ was "Useful" in the first quarter of 2015. In the second quarter of 2018 that percentage increases to $46 \%$.

(b)

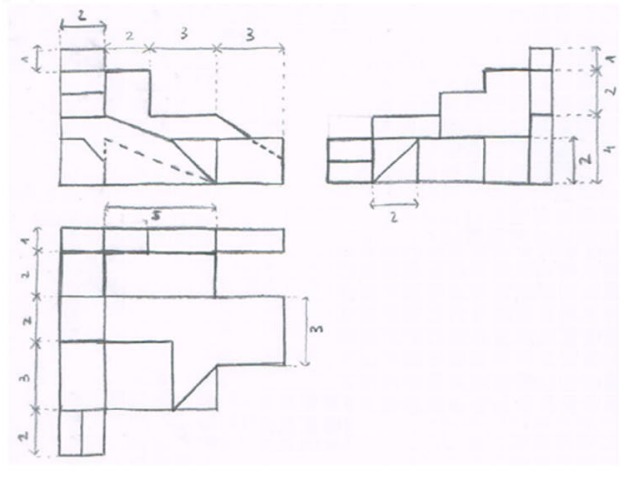



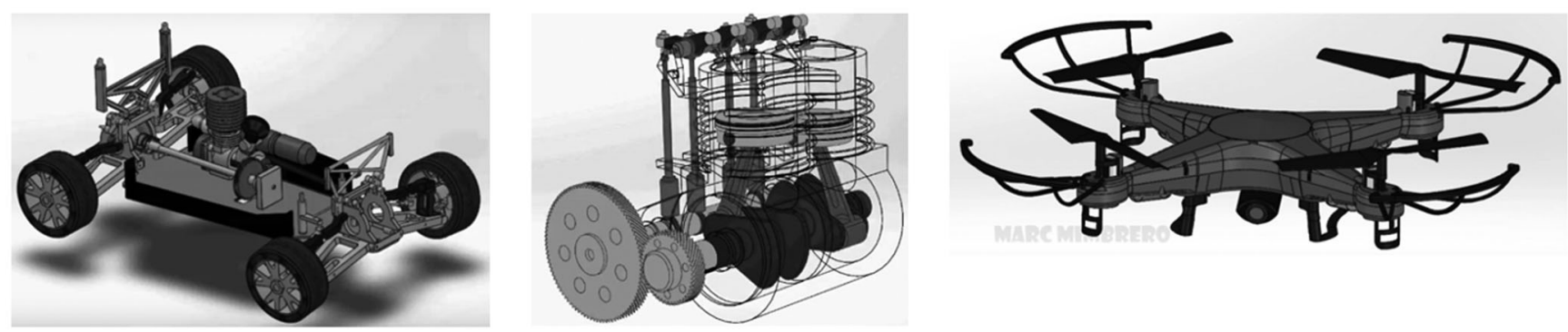

FI G URE 8 Different projects completed by the project groups.

When asked if they had understood and learned the course content, a high percentage of the students "Agree" as can be seen in Figure 16.

Figure 17 shows the responses related to the question about whether the study material contributes to improving the assessment and understanding of the subject. Although unevenly in the positive responses, but with a growing trend in the "Agree" response, it stands out that "Disagree" remains constant throughout the years.

Finally, regarding the workload of the course, the students appreciate (Figure 18a) a notable decrease in the workload over time. It is perceived that the students do not consider that the application of the active-learning methodologies suppose an additional effort in their studies.

Regarding the speed of the course, in Figure 18b, the students consider that the course has been slightly fast with a slight increase over the 4 years. Likewise, the "Normal" response remains almost unchanged throughout the years.

\section{4 | DISCUSSION}

The incorporation of new degrees from the EHEA has meant a rethinking of the theoretical and practical contents in the subject GE. The introduction of activelearning methodologies has implied advances in the teaching of space geometry with the incorporation of new activities inside and outside the classroom and new teaching-learning models. The expository/master sessions on representation systems and 2D mapping methods have decreased in favor of an increase in CAD practices.

With the introduction of these active-learning activities, the aim has been to improve relevant learning and for the student to restructure their previous mental schemes through the analysis, understanding, reworking, work, assimilation, and treatment of the information proposed in an active way. The

TABLE 12 Parts and evaluation of the project

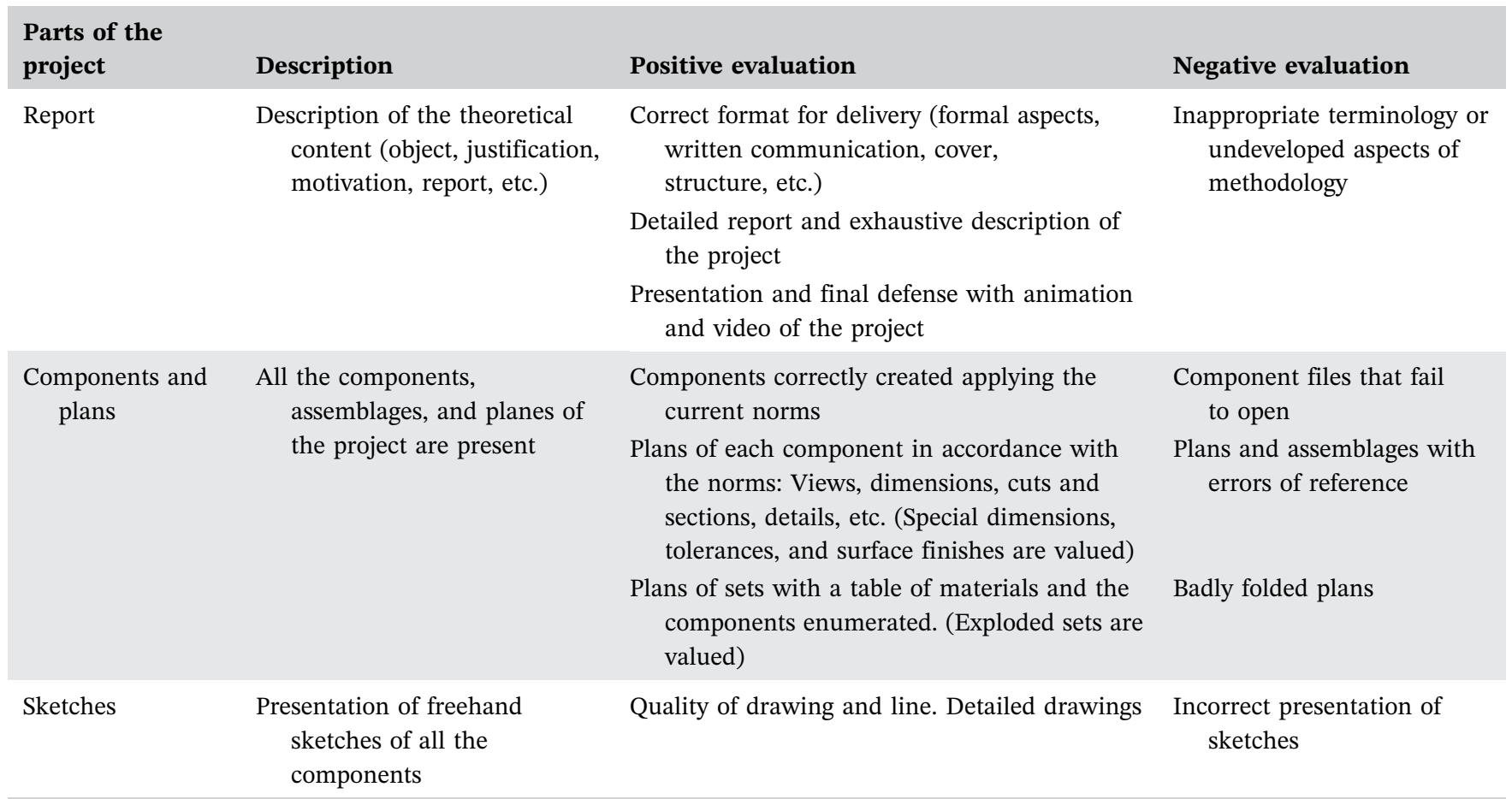


TABLE 13 Average marks of the projects and final marks of the groups from 2015 to 2018, compared to the final marks from 2011 to 2014

\begin{tabular}{|c|c|c|c|}
\hline $\begin{array}{l}\text { Quarter/ } \\
\text { year }\end{array}$ & Group & $\begin{array}{l}\text { Mark average } \\
\text { project (out 10) }\end{array}$ & $\begin{array}{l}\text { Final mark } \\
\text { average (out 10) }\end{array}$ \\
\hline 1Q/2011 & M22 & No mark & 5.7 \\
\hline $2 \mathrm{Q} / 2011$ & A11 & No mark & 5.3 \\
\hline 1Q/2012 & M22 & No mark & 5.5 \\
\hline 1Q/2012 & M61 & No mark & 5.6 \\
\hline $2 Q / 2012$ & A11 & No mark & 5.9 \\
\hline 1Q/2013 & M61 & No mark & 5.5 \\
\hline $2 \mathrm{Q} / 2013$ & M22 & No mark & 5.9 \\
\hline $2 Q / 2013$ & M52 & No mark & 6.1 \\
\hline $1 \mathrm{Q} / 2014$ & M22 & No mark & 6.5 \\
\hline $2 Q / 2014$ & M52 & No mark & 6.6 \\
\hline $1 \mathrm{Q} / 2015$ & M22 & 8.1 & 6.7 \\
\hline $1 Q / 2015$ & M52 & 8.2 & 6.7 \\
\hline $2 \mathrm{Q} / 2015$ & M52 & 8.2 & 6.3 \\
\hline 1Q/2016 & M71 & 5.4 & 5.6 \\
\hline $2 Q / 2016$ & M51 & 7.6 & 6.1 \\
\hline $2 \mathrm{Q} / 2016$ & M61 & 7.9 & 6.6 \\
\hline 1Q/2017 & $\mathrm{A} 21$ & 6 & 5.9 \\
\hline $2 \mathrm{Q} / 2017$ & M32 & 7.6 & 5.7 \\
\hline $2 \mathrm{Q} / 2017$ & M61 & 7.4 & 5.8 \\
\hline $1 Q / 2018$ & M12 & 6.9 & 5.7 \\
\hline $2 Q / 2018$ & A32 & 5.6 & 6.1 \\
\hline
\end{tabular}

application of these active-learning methodologies have allowed the acquisition of new, more complex skills and bring students closer to a more realistic vision of teamwork [43].
It may seem (Figure 9) that the results of the final marks worsen over the years, especially from 2016. This is due to three main reasons. First, the demands on the deliverables, assignments, and exercises increased as the academic years progressed. Second, during the first 2 years (2015 and 2016), all evaluations were rated without rubrics. Since the implementation of the rubrics in 2016, the marks have been developed with a more global and general evaluation of student performance. And third, the adjustment of the formative evaluation. In this process, the teachers of the subject have shared common learning goals, and there has been deliberation on the progress of the students in relation to the learning objectives. This adjustment in the process is made to determine the best way to expand the teaching and learning process according to the needs of each course. In short, the requirements are being readjusted to achieve a balance throughout the courses.

\subsection{Discussion on the FC methodology}

In relation to the results obtained with respect to the application of FC, the analysis of the performance of the voluntary tests shows us that if the student performs more than four tests, they have many possibilities of passing the subject. Although these data are not conclusive in themselves, the observation made during years of teaching (as an evaluation instrument $[29,37])$ has allowed this perception. It is a summative evaluation where the final mark depends on several other marks. What prevails is the student's motivation to take these tests, although it is assumed that many students will not perform the tasks scheduled in the time provided before class, as described by Harrison [39]. The use of FC largely depends on the type of

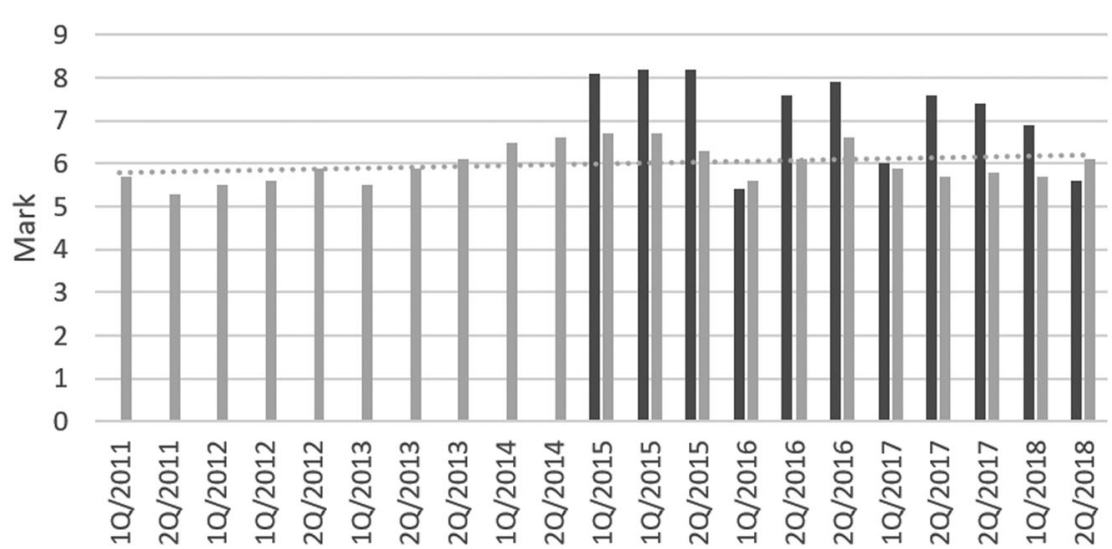

Average project mark Average final mark
Lineal (Average final mark)
FIGURE 9 Averages of the marks of the projects and final marks of the groups from 2018 and final marks from 2011 to 2014 
TA B LE 14 SEEQ survey questions, weighted averages, and standard deviations.

\begin{tabular}{|c|c|c|}
\hline SEEQ survey questions & $\begin{array}{l}\text { Weighted average } \\
\text { (out of 5) (2015-2018) }\end{array}$ & $S D$ \\
\hline \multicolumn{3}{|l|}{ Evaluate the use of the following learning activities: } \\
\hline Tutorials & 3.09 & 0.75 \\
\hline Test & 2.72 & 0.7 \\
\hline Sketch & 2.59 & 0.95 \\
\hline Project & 3.18 & 0.79 \\
\hline $\begin{array}{l}\text { I tried, in general, to complete the assigned distance- } \\
\text { based activities (tutorials, tests, etc.). }\end{array}$ & 2.54 & 0.67 \\
\hline I have participated actively in group work sessions. & 4.61 & 0.67 \\
\hline $\begin{array}{l}\text { The work groups are a good means of learning about } \\
\text { the subject and sharing ideas and knowledge. }\end{array}$ & 3.92 & 1 \\
\hline $\begin{array}{l}\text { The application project is very useful for a better } \\
\text { understanding of the course as well as for learning } \\
\text { to organize an assignment and finding practical } \\
\text { applications. }\end{array}$ & 4.19 & 0.91 \\
\hline I have learned and understood the contents & 4.26 & 0.66 \\
\hline $\begin{array}{l}\text { The bibliography, additional material, assignments, } \\
\text { etc., contribute to improving the evaluation and } \\
\text { understanding of the subject. }\end{array}$ & 4.13 & 0.89 \\
\hline $\begin{array}{l}\text { The workload of this course compared to others } \\
\text { has been }\end{array}$ & 3.57 & 0.9 \\
\hline The course has been & 3.62 & 0.76 \\
\hline
\end{tabular}

Abbreviation: SEEQ, Students' Evaluation of Educational Quality. student and subject, which can vary in the preparation of the classes, the reasoning capacity, or the selfdirected learning skills. This statement can be extrapolated to different types of courses and different maturity evaluations of the students throughout their studies. In addition, the application of this methodology has led to a reduction in the teaching workload associated with the time of preparation and delivery of the class, a conclusión that is in good agreement with Rhaman [68] and Fedesco [30]. Reducing face-to-face teaching gives the teacher more time for individual interaction. In this way, the teacher gains a better understanding of comprehension problems and repair the misconceptions of students.
FIGURE 10 Evaluate the use of the following learning activities. Project. (2015-2018)

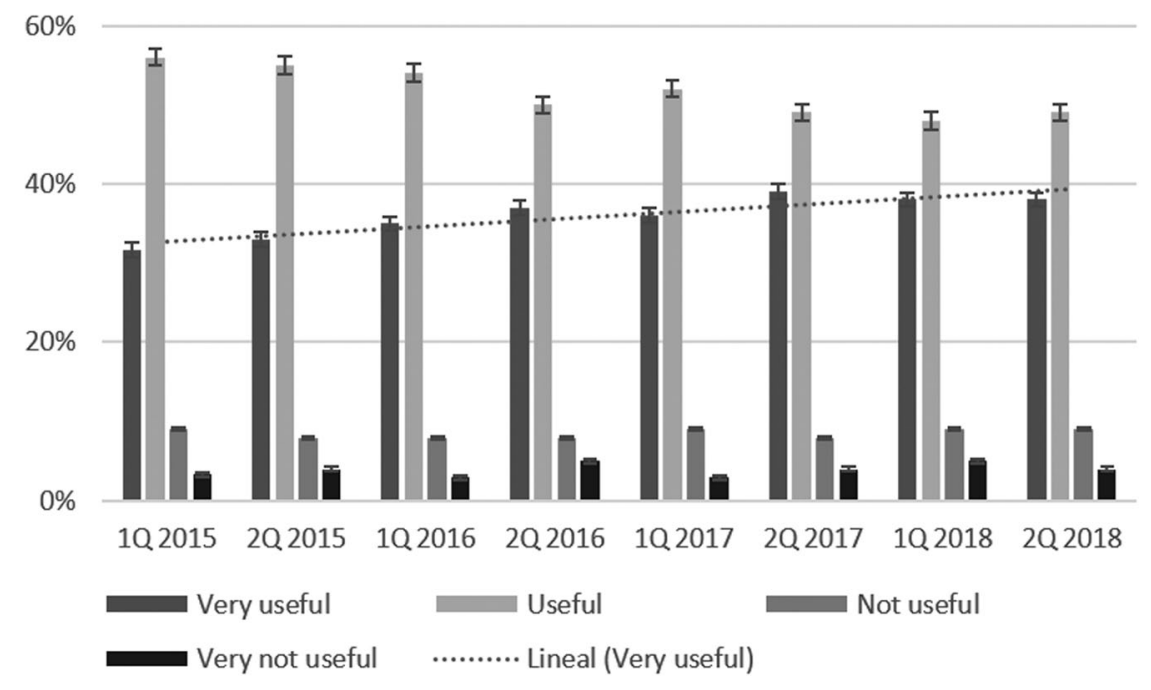


$60 \%$

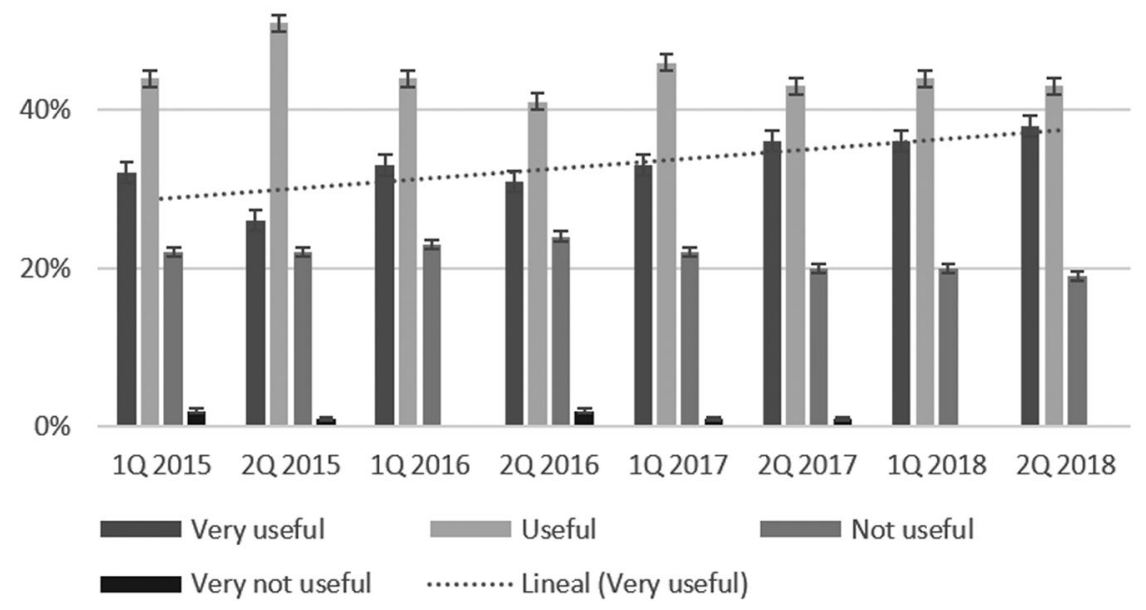

(a)

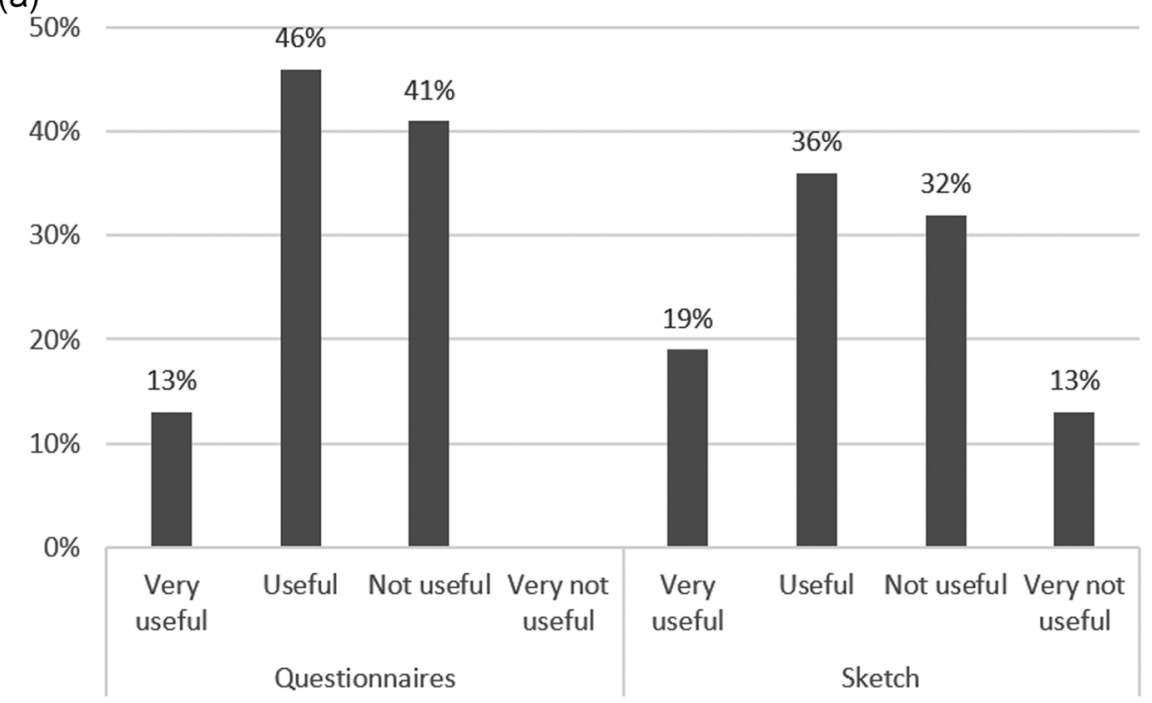

(b)

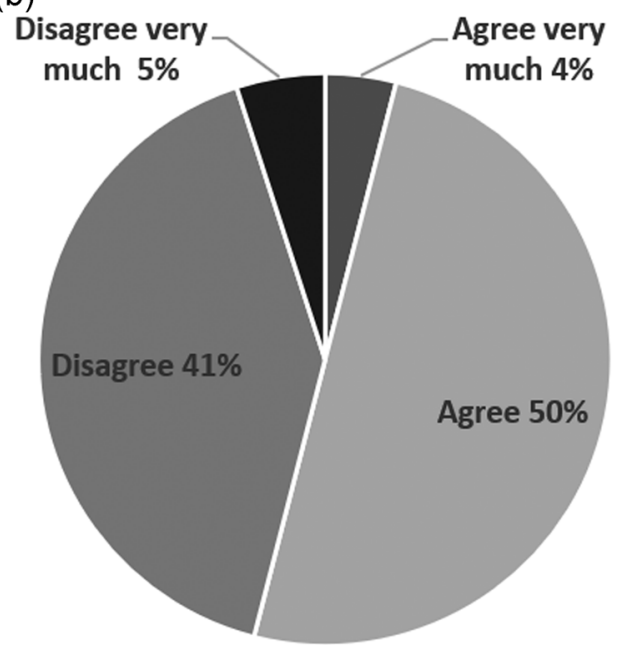

FIGURE 11 Evaluate the use of the following learning activities. Tutorials. (2015-2018) 
FIGURE 13 I have participated actively in the sessions of work in a group

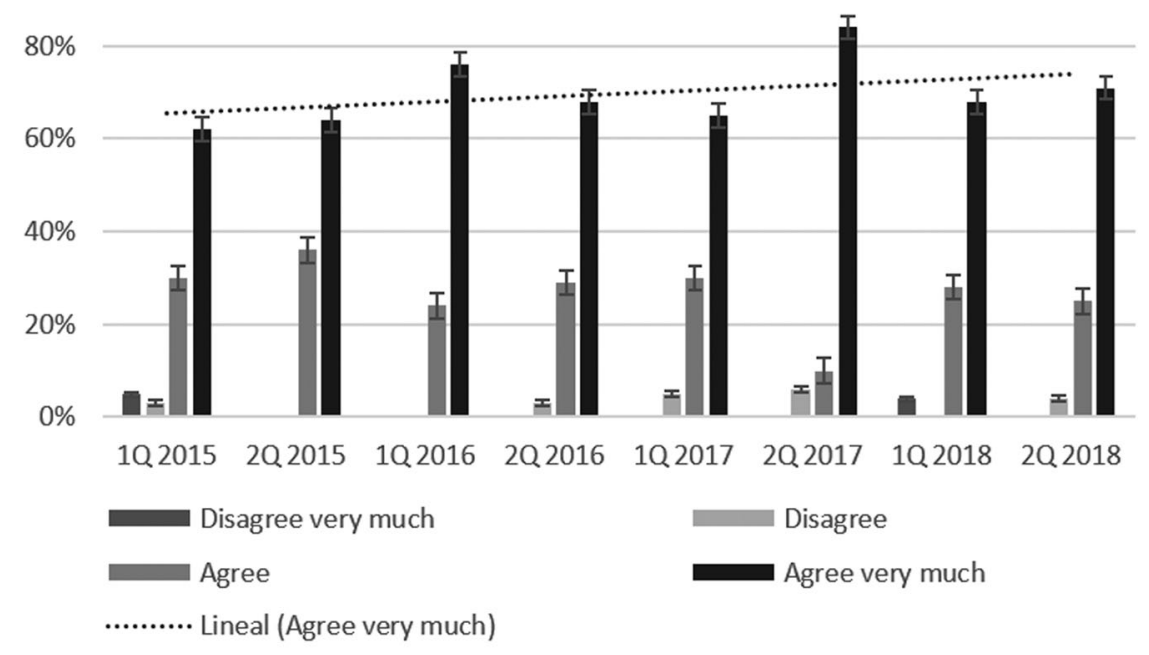

FIGURE 14 The work groups are a good means of learning about the subject and sharing ideas and knowledge

FIG URE 15 The application project is very useful for a better understanding of the course as well as for learning to organize an assignment and finding practical applications
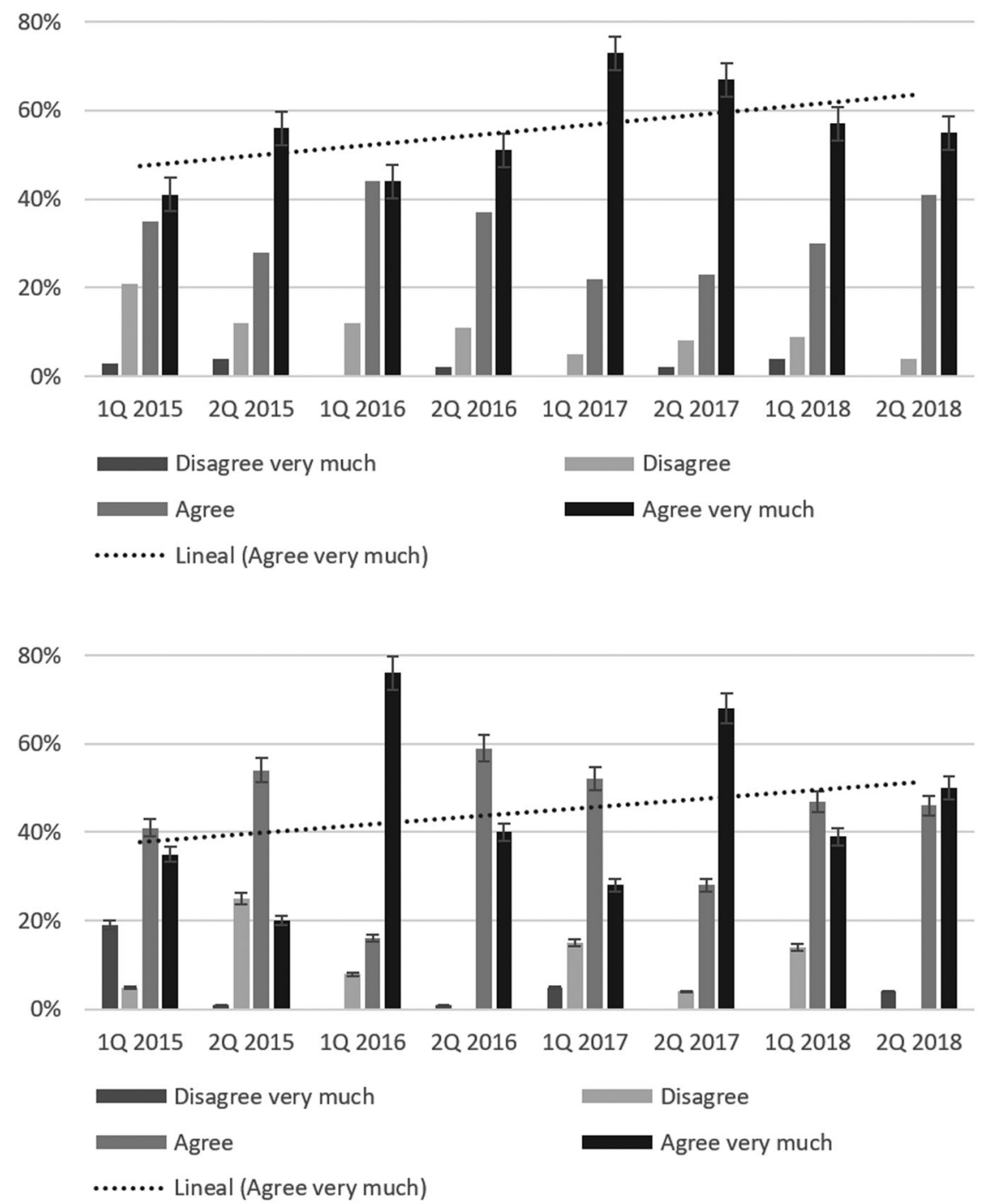

Some researchers reported that the FC approach improved the academic ability and performance of the participants $[24,45,79]$, and several points in common with other authors can be extracted [2,59], on the application of this methodology. For example, the introduction of content in advance, the involvement and motivation of teachers and students, and the introduction and planning of cooperative learning activities and what 


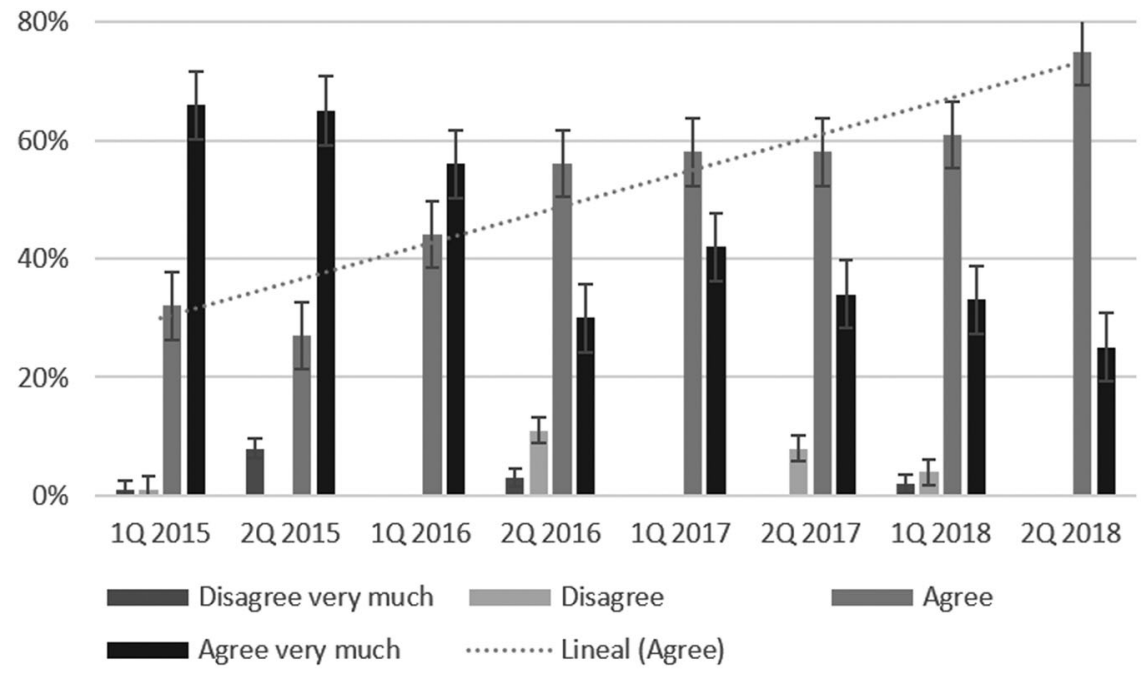

FIGURE 16 I have learned and understood the contents

was exposed by Karabatak [47] who reported that the levels of academic performance of students in the FC were significantly higher than that of the students in the traditional classroom model and its application led to a significant change in their motivation. Still, the literature shows increasing evidence that the application of FC improves academic performance, although some are inconclusive [2]. The findings in the Frydenberg [34] and Winter [86] studies were not consistent with the findings of this study. Using a CF approach, Frydenberg found no increase in student achievement compared to the traditional approach. On the other hand, Winter did not observe an increase in the performance of the students who used this methodology.

For the success of this methodology, the student must have studied it before starting the scheduled class. Students should receive the information for themselves before and not during the teacher's explanation in the classroom. This assimilation of information promotes self-knowledge, and it is necessary to insist on reaching everyone at the same level to start discussing doubts. It is found that this is not always the case. The difference in level has been perceived to cause a delay in the progress of the less advanced students.

\section{2 | Discussion on the DT methodology}

Regarding the application of the DT methodology, the importance of the visual aspect in student learning is highlighted. They take advantage of the recommended exercises to discover ideas and develop them quickly and intuitively. It is perceived that this is the environment where their learning experience is best developed with a high level of motivation in carrying out the tasks assigned, and they respond to them with great interest. In the same way, as manifested in Levine's experience [49], students appreciated the incorporation of the DT process throughout the course. This is also due to the high degree of attention they pay as it is a compulsory first cycle subject. According to Cutumisu [21], a possible interpretation is that the students who exhibit higher

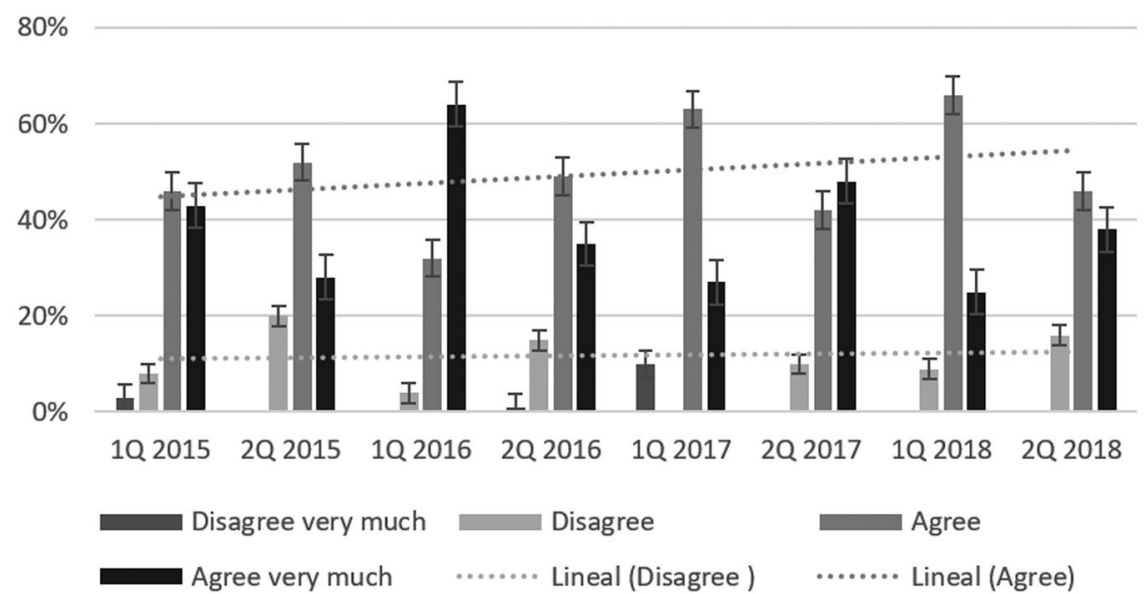

FIG URE 17 The bibliography, the additional material, the assignments, etc., contributed to improving the assessment and understanding of the subject 
FIGURE 18 (a) The workload of this course compared to others, has been. (b) The course has been

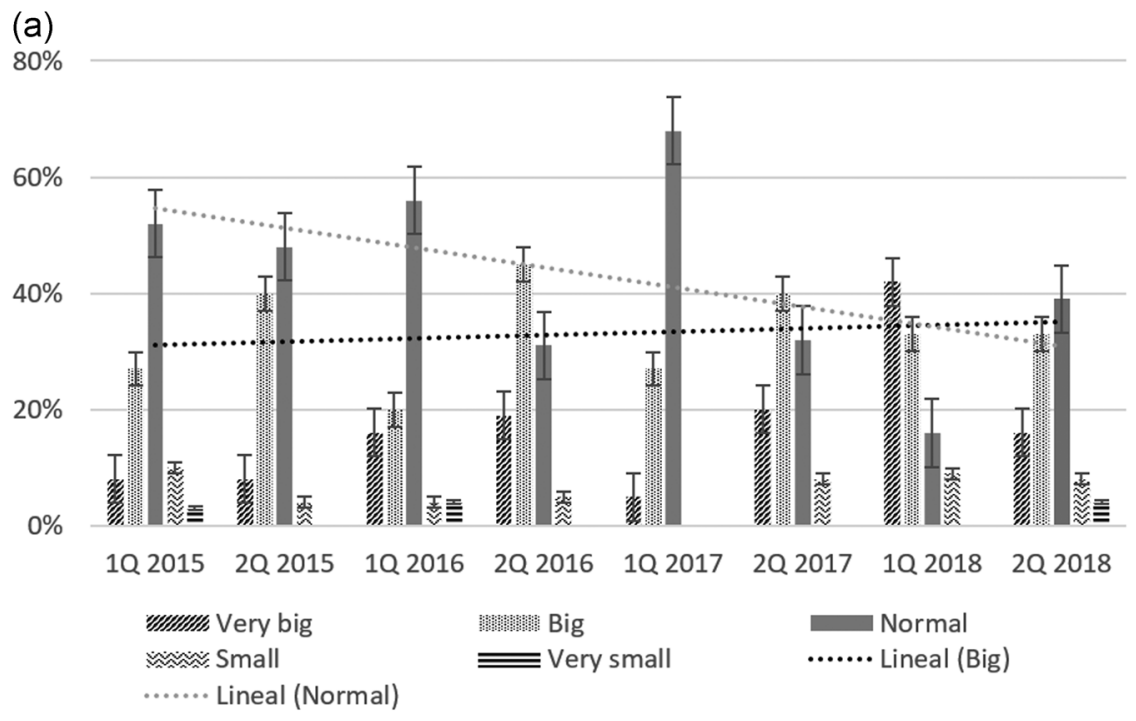

(b)

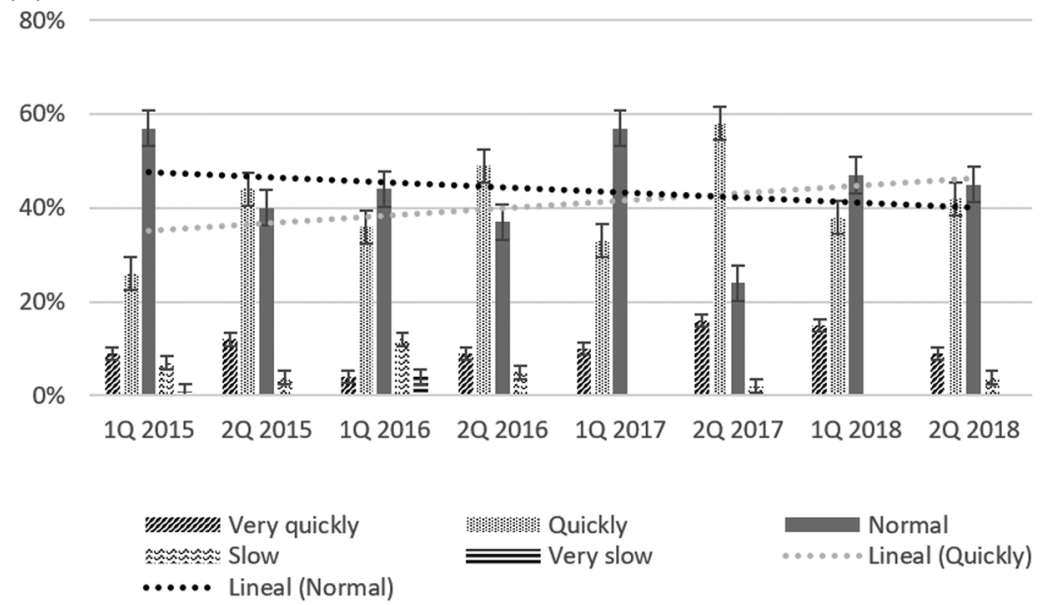

academic performance reached these levels because they had spontaneously used these strategies during their academic studies and obtained better performance when learning independently and adapting to ever-changing environments.

Those students who show a low level of learning from the beginning of the classes are provided with a series of individualized exercises (in addition to the practices with tutorials and the video resolution) so that they practice their execution and manage to catch up with the rest of the class.

Although viewing the exercise solution (on video) does not appear responsible for changes in learning performance, it may provide additional time for other activities [23]. It is clear that individual instruction with the computer outside the classroom must be complemented by other tasks that support it.

We believe that in the application of this methodology, it is necessary to train teachers in the domain of skills that allow the development and application of DT in teaching inside and outside the classroom and in student learning, facilitating new methodological strategies for graphic representation of learning content. McGrath's studies [57] are supported by the same idea. Virtual or distance learning methodologies and environments are crucial to the future of learning. Collaboration across disciplines is needed to articulate this methodology and conduct more studies that assess the value of design learning, including studies of how to assess design learning.

\section{3 | Discussion on the VT methodology}

On the application of the VT methodology, it is verified that the making of freehand sketches for the modeling of solids is ideal for introducing drawing in the study plans of the first-year subjects in engineering degrees and serves as a complement to the development of subjects that incorporate design in the following courses.

This is intended to be a wake-up call to avoid falling into what Ullman [82] pointed out in the 90's. He said 
that most of the engineers were trained in writing but not in sketches, so that Linsey 20 years later [50] would make a similar observation: "In general, engineers are not taught to draw, and their ability to draw may be lacking." The graphic tools and skills training aims to empower students to have more confidence in their skills and analytical tools, as expressed by Ferguson [31] so as not to create mediocre engineers.

The application of this active-learning methodology ensures that students develop and internalize good design practices with an impact on the product design process. In addition, it helps to understand the realization of parts when using some solid modeling software and allows to make complex ideas more accessible and summarize them in main ideas. Freehand drawing aims to create a tool to encourage creativity and aid VT. The student learns to represent the technical specifications for the manufacture of a product, showing in the sketch the actual measurements of the object, details, and manufacturing specifications. Additionally, it has allowed you to think differently, be more observant, increase creativity, and help them communicate more effectively.

Drawing sketches of freehand parts have been observed during sketching classes as a means of solving problems, generating ideas and concepts according to Bilda [9] and Eissen and Steur [27]. There is sufficient evidence that quick sketches aid visualization and therefore allow students to explore the creative design space more effectively $[9,80]$.

\section{4 | Discussion on the Project Based Learning methodology}

In relation to the application of the PBL methodology, the evaluation of the generic autonomous learning competence (assigned for the subject) has been promoted together with the specific ones of the subject and the transversal skills and aptitudes (organization and planning, teamwork, leadership, etc.).

Skills and knowledge that students possess or have previously learned have been fostered, and solutions to an undefined problem have been sought. The application of the PBL methodology has fostered the practice of critical thinking and generated processes of self-reflection on the student's own learning.

The quality shown, the high level of complexity, and the high final marks of the projects carried out make us perceive that the students have fully developed this competence. This project is carried out completely outside classroom hours, and the group of students has applied in the project all the knowledge acquired during the course. They have also learned to work collaboratively to find solutions to real-life problems.

It is observed (see Table 13 and Figure 9) that the marks of the project groups are, in general, high (7 on average), which shows their interest and enthusiasm. Starting in the first quarter of 2016, projects were evaluated with rubrics, so there is a difference in the marks compared to 2015 .

\section{5 | Discussion on the student satisfaction survey}

Based on the results of the survey, it is perceived that the incorporation of different active-learning methodologies allows improving the academic results of the students and the satisfaction, as well as the reduction of the weekly workload assigned to the student and allows to improve the learning process in the development of teaching activities, in addition to promoting creative and innovative thinking. It has also contributed to the improvement in the visualization of geometric models and the understanding of statements and solutions, allowing to reduce the time in theoretical expositions.

The results of the survey perceive that favoring the continued use of active-learning methodologies improves the performance of participating students, especially when these active-learning methodologies become innovative for students, as other authors agree $[36,38,67]$.

These teaching methodologies have been applied since 2015 in this subject (authors' publications [60-62]) with satisfactory results. The slightly increasing trend (Figure 9) in the final marks of the subject demonstrates this, as does the increase in satisfaction with the performance of the different methodologies.

\section{5 | CONCLUSIONS}

To test the hypothesis that implementing active-learning methodologies improves student learning and performance, a longitudinal and quantitative study of these teaching practices was carried out in 11 class groups in the subject GE during the years 2015 to 2018. The final marks (including the marks of the final project) were compared with the marks obtained by the students in previous years (2011 to 2014). A survey with a sample of 271 students was used to analyze data that reported on satisfaction in carrying out these activities and the workload of the subject.

Teachers must begin to question the teaching of traditional classes in daily practice. Although these classes continue to have strong advocates, the administrations 
and the university itself must support the implementation of these practices, firstly, to the teachers most sensitive to teaching innovation and concerned with improving university training, and second, so that finally be of current application to all teachers. Universities must be persuaded to reevaluate their teaching methodologies to adapt to these changes, with fewer conferences and more activities that promote skills and attitudes.

In light of recent work indicating that active learning provides benefits to students from disadvantaged backgrounds and to women in male-dominated fields, the implementation of these teaching practices in underrepresented groups or minorities is especially relevant to enhance integration, self-esteem, and the ability to lead working groups.

The use of these active-learning techniques can inspire other authors to translate them into their own contexts and apply them to other areas where the technological component has a considerable influence on the content of the subject. The future work of this study should focus on transferring this effort to overturn the contents and strategies to the implementation of the classes in a blended way and better understand the implementation of these methodologies in other fields or areas in the different degrees of engineering.

\section{ACKNOWLEDGMENTS}

We thank all the students enrolled in the subject GE who responded to the survey on active learning.

\section{DATA AVAILABILITY STATEMENT}

Data available on request from the authors. The data that support the findings of this study are available from the corresponding author upon reasonable request.

\section{ORCID}

Noelia Olmedo-Torre (1) http://orcid.org/0000-0003-

2502-3201

María Martínez Martínez (i) http://orcid.org/0000-00032137-8048

Marta Peña (1) http://orcid.org/0000-0003-3889-8584

\section{REFERENCES}

1. ABET Engineering Accreditation Commission, Accreditation board for engineering and technology, Criteria for accrediting engineering programs, 2019-2020. Criterion 3. Student outcomes, 2019, available at: https://www.abet.org/ accreditation/accreditation-criteria/criteria-for-accreditingengineering-programs-2019-2020/\#GC3

2. G. Akçayır and M. Akçayır, The flipped classroom: A review of its advantages and challenges, Comput. Educ. 126 (2018), 334-345.
3. I. Allen and J. Seaman, Going the distance: Online education in the United States, Electronics Letters, vol. 48, no. 13, M. S. C. Newbury Port, ed. 2011, p. 742.

4. E. Aspden and L. Thorpe, Where do you learn? Tweeting to inform learning space development 32, Educause Quarterly, Washington, DC, (2019), no. 1.

5. N. Augustine, Rising above the gathering storm: Energizing and employing America for a brighter economic future, The National Academic Press, Washington, DC, 2007, pp. 1-564.

6. O. Ayala, O. Popescu and V. Jovanovic, Flipped classroom as blended learning in a fluid mechanics course in engineering technology, Conference Proceedings of ASEE Annual Conference \& Exposition, vol. 2017, 2017.

7. R. Beichner et al., The student-centered activities for large enrollment undergraduate programs (scale-up) project abstract, Physics. 1 (2007), no. 1, 1-42.

8. J. Bergmann and A. Sams, Flip your classroom: Reach every student in every class every day, SGEM2016 Conference Proceedings, vol. 3, 2012, ISBN 978-619-7105-72-8/ISSN 2367-5659.

9. Z. Bilda, J. Gero and T. Purcell, To sketch or not to sketch? That is the question, Des. Stud. 27 (2006), no. 5, 587-613.

10. J. Bishop and M. Verleger, Testing the flipped classroom with model-eliciting activities and video lectures in a mid-level undergraduate engineering course, Proceedings of Frontiers in Education Conference (FIE), 2013, pp. 161-163.

11. E. Borda et al., Initial implementation of active learning strategies in large, lecture STEM courses: Lessons learned from a multi-institutional, interdisciplinary STEM faculty development program, Int. J. STEM Educ. 7 (2020), no. 1, 4.

12. D. Boude and Associates, Assessment 2020: Seven propositions for assessment reform in higher education, Educ. Train. (2010), 330-333.

13. J. Bransford, A. Brown and R. Rodney, Centered on education research, J. Eng. Educ. 94 (2005), no. 1, 195-197.

14. T. Brown, Design thinking, Harvard Business School Publishing Corporation, EEUU, Boston, MA, 2008.

15. C. Brown, K. Danvers and D. Doran, Student perceptions on using guided reading questions to motivate student reading in the flipped classroom, Account. Educ. 25 (2016), no. 3, 256-271.

16. D. Chasanidou, A. A. Gasparini and E. Lee, Design thinking methods and tools for innovation in multidisciplinary teams, Innov. HCI what can we Learn from Des. thinking? 1 (2014), 27-30.

17. A. Chickering, and Z. Gamson, Siete principios de buenas prácticas en la educación, ERIC - Inst. Educ. Sci (1987.

18. E. Coleman et al., Design thinking among first-year and senior engineering students: A cross-sectional, national study measuring perceived ability, J. Eng. Educ. 109 (2020), no. 1, 72-87.

19. S. Condoor, Integrating design in engineering graphics courses using feature-based, parametric solid modeling, Proceedings of Frontiers in Educational Conference, vol. 2, 1999, pp. 13-17.

20. T. Conlon, A review of informal learning literature, theory and implications for practice in developing global professional competence, J. Eur. Ind. Train. 28 (2004), no. 2/3/4, 283-295.

21. M. Cutumisu, D. L. Schwartz and N. M. Lou, The relation between academic achievement and the spontaneous use of designthinking strategies, Comput. Educ. 149 (2020), 103806.

22. P. Del Canto et al., Follow-up and feedback processes in the Ehea, J. Technol. Sci. Educ. 1 (2011), no. 1, 12-22. 
23. S. DeLozier and M. Rhodes, Flipped classrooms: A review of key ideas and recommendations for practice, Educ. Psychol. Rev. 29 (2017), no. 1, 141-151.

24. L. Deslauriers, Improved learning in a large-enrollment physics class, Science. 862 (2011), no. May, 862-864.

25. S. Eddy and K. Hogan, Getting under the hood: How and for whom does increasing course structure work? CBE. Life. Sci. Educ. 13 (2014), no. 3, 453-468.

26. EEBE, Teaching guide EG-EEBE. Plan of studies of degree in engineering, UPC, 2020, available at: https://www.upc.edu/ estudispdf/guia_docent.php?codi=820003\&lang=en

27. K. Eissen and R. Steur, Sketching: The basics, Google Scholar, Amsterdam, 2012.

28. N. Eng, M. Aurisicchio and R. Bracewell, Mapping software augments engineering design thinking, J. Mech. Des. Trans. ASME 139 (2017), no. 5.

29. Evalfor, Evaluación en Contextos Formativos-Universidad de Cádiz, 2020, available at: https://sej509.uca.es/

30. H. Fedesco and C. Troy, Why this flip wasn't a flop: What the numbers don't tell you about flipped classes, Conference Proceedings of ASEE Annual Conference \& Exposition, vol. 2016, 2016.

31. E. Ferguson, Engineering and the mind's eye, The MIT Press, London, 1994.

32. N. Fila, S. McKIlligan and K. Guerin, Design thinking in engineering course design, Conference Proceedings of ASEE Annual Conference \& Exposition, vol. 2018, 2018.

33. S. Freeman et al., Active learning increases student performance in science, engineering, and mathematics, Proc. Natl. Acad. Sci. USA. 111 (2014), no. 23, 8410-8415.

34. M. Frydenberg, Flipping excel, Proceedings of ISECON (Information Systems Educational Conference), vol. 29, 2012, pp. 1-11,

35. G. Goldschmidt, On visual design thinking: The vis kids of architecture, Des. Stud. 15 (1994), no. 2, 158-174.

36. D. Haak et al., Increased structure and active learning reduce the achievement gap in introductory biology, Science (80-.). 332 (2011), no. June, 1213-1216.

37. C. Hamodi, V. Pastor and A. Pastor, Medios, técnicas e instrumentos de evaluación formativa y compartida del aprendizaje en educación superior, Perfiles Educ. 37 (2015), no. 147 146-161.

38. J. Handelsman et al., Scientific teaching, Science. 304 (2004), no. 5670, 521-522.

39. D. Harrison et al., Assessing the effectiveness of a hybrid-flipped model of learning on fluid mechanics instruction: overall course performance, homework, and far-and near-transfer of learning, Eur. J. Eng. Educ. 42 (2017), no. 6, 712-728.

40. J. Hehn et al., On integrating design thinking for humancentered requirements engineering, IEEE Softw. 37 (2020), no. 2 , 25-31.

41. A. Heinze and C. Procter, Reflections on the use of blended learning, Conference Proceedings of the Conference Education in a Changing Environment (2004), no. September, 1-12.

42. Y. Hussain and M. Jaeger, $L M S$-supported PBL assessment in an undergraduate engineering program-Case study, Comput. Appl. Eng. Educ. 26 (2018), no. 5, 1915-1929.

43. ICE-UPC, El aprendizaje activo: Una nueva forma de enseñar y aprender, Barcelona, 2006.
44. A. Jamieson et al., The benefits of higher education study for part-time students, Stud. High. Educ. 34 (2009), no. 3, 245-262.

45. J. S. Jeong, D. González-Gómez, and F. Cañada-Cañada, Students' perceptions and emotions toward learning in a flipped general science classroom, J. Sci. Educ. Technol. 25 (2016), no. $5,747-758$.

46. D. W. Johnson, R. T. Johnson and K. A. Smith, Cooperative learning: Improving university instruction by basing practice on validated theory, J. Excell. Coll. Teach 25 (2014), 85-118.

47. S. Karabatak and H. Polat, The effects of the flipped classroom model designed according to the ARCS motivation strategies on the students' motivation and academic achievement levels, Educ. Inf. Technol. 25 (2020), no. 3, 1475-1495.

48. M. Karlin, and N. Viani, Project-based learning, Jackson Education Service District, Medford, OR, 2001.

49. D. Levine and A. Agogino, Design thinking in development engineering, Int. J. Eng. Educ. 32 (2016), no. 3, 1396-1406.

50. J. Linsey et al., A study of design fixation, its mitigation and perception in engineering design faculty, J. Mech. Des. Trans. ASME 132 (2010), no. 4, 0410031-04100312.

51. S. Loyens, J. Magda, and R. Rikers, Self-directed learning in problem-based learning and its relationships with self-regulated learning, Educ. Psychol. Rev. 20 (2008), no. 4, 411-427.

52. A. Mabogunje, N. Sonalkar and L. Leifer, Design thinking: $A$ new foundational science for engineering, Int. J. Eng. Educ. 32 (2016), no. 3, 1540-1556.

53. A. Maldonado and M. Morales, Modelling dependency structures produced by the introduction of a flipped classroom, Mathematics. 8 (2019), no. 1, 19.

54. H. Marsh, Students' evaluations of university teaching: Research findings, methodological issues, and directions for future research, 1987.

55. E. Mart et al., PBL on line: A proposal for the organization, parttime monitoring and assessment of $P B L$ group activities, J. Techonology Sci. Educ. 5 (2015), no. 2, 87-96.

56. R. Martín et al., SEEQ questionnaire for validating the teaching improvement when introducing digital storytelling in higher education, J. Adv. Theor. Appl. Inform. 3 (2017), no. 1, 98.

57. M. McGrath and J. Brown, Visual learning for science and engineering, IEEE. Comput. Graph. Appl. 25 (2005), no. 5, 56-63.

58. J. Mena Lorenzo et al., Estilos de aprendizaje del alumnado de ingeniería: Curso, rendimiento y género, European Journal of Education and Psychology 12 (2019), no. 2, 175.

59. J. O'Flaherty and C. Phillips, The use of flipped classrooms in higher education: A scoping review, Internet High. Educ. 25 (2015), 85-95.

60. N. Olmedo-Torre, Perception of the acquisition of generic competences in engineering degrees, Int J Technol Des Educ. 28 2018(no). 495-506. https://doi.org/10.1007/s10798-016-9390-z

61. N. Olmedo-Torre et al., The influence of ICT on learning in graphic engineering, Proc. Soc. Behav. Sci. 237 (2017), no. June 2016, 737-744.

62. N. Olmedo-Torre and M. Martínez, Detection of training deficiencies in the autonomous learning of graphic engineering students: A university teacher training experience based on competencies, Int. J. Eng. Educ. 34 (2018), no. 5, 1592-1603.

63. N. Olmedo-Torre and M. Martínez Martínez, Evaluación de la competencia de aprendizaje autónomo en grados de ingeniería de la Universitat Politècnica de Catalunya, CIDUI-Congreso 
Internacional de Docencia Universitaria e Innovación, 2016, pp. 950-961.

64. D. Owens, T. Angela, and Cindi Smith-Walters, Student motivation and resistance in active learning classrooms, Act. Learn. Coll. Sci.- (2020), 927-942.

65. R. Oxman, Computational support for visual thinking in design ideation, Proceedings of IEEE Symposium on Information Visualization, 1998, pp. 192-195.

66. V. Pastor, Best practices in academic assessment in higher education, J. Technol. Sci. Educ. 1 (2011), no. 2, 25-39.

67. M. Prince, Does active learning work? A review of the research, J. Eng. Educ. 93 (2004), no. 3, 223-231.

68. A. Rahman et al., Implementation strategy of project based learning through flipped classroom method, IEEE Conference on e-Learning, e-Management and e-Services, IC3e 2016, 2016, pp. 1-5.

69. A. Rahman, A blended learning approach to teach fluid mechanics in engineering, Eur. J. Eng. Educ. 42 (2017), no. 3, 252-259.

70. P. Ramsden, A performance indicator of teaching quality in higher education: The course experience questionnaire, Stud. High. Educ. 16 (2006), no. 2, 129-150.

71. C. Romero, Design thinking, creatividad y realismo para resolver problemas, vol. 14, no 01, 2012, available at: http://estebanromero. com/2012/09/design-thinking-creatividad-y-realismo-para-resolverproblemas/

72. P. Sancho et al., Applying multiplayer role-based learning in engineering education: Three case studies to analyze the impact on students' performance, Int. J. Eng. Educ. 25 (2009), 665.

73. M. Schwartz and S. Pollishuke, Aprendizaje activo: una organización de la clase centrada en el alumnado. 1995.

74. M. Schütze, P. Sachse and A. Römer, Support value of sketching in the design process, Res. Eng. Des. 14 (2003), no. 2, 89-97.

75. J. Shuman, M. Besterfield-Sacre and J. Gourty, The ABET 'professional skills'-Can they be taught? Can they be assessed? J. Eng. Educ. 94 (2005), no. 1, 41-55.

76. H. Simon, The sciences of the artificial, vol. 11, no. 1. 1970.

77. C. Soledad and G. González, Estrategias para trabajar la creatividad en la Educación Superior pensamiento de diseño, aprendizaje basado en juegos y en proyectos, RED. Rev. Educ. a Distancia, vol. unknown no. 40 (2014), 7-22.

78. B. Stockwell et al., Blended learning improves science education, Cell 162 (2015), no. 5, 933-936.

79. P. Strelan, A. Osborn and E. Palmer, Student satisfaction with courses and instructors in a flipped classroom: A meta-analysis, J. Comput. Assist. Learn. 36 (2020), no. 3, 295-314.

80. E. Taborda et al., Enhancing visual thinking in a toy design course using freehand sketching, Proceedings of ASME Design Engineering Technical Conference, vol. 7, 2012, pp. 267-276.

81. M. Tovey, S. Porter and R. Newman, Sketching, concept development and automotive design, Des. Stud. 24 (2003), no. 2, 135-153.

82. R. Ullmann, Towards the development of FSL teacher competencies: Some thoughts on future teacher education programs, Can. Mod. Lang. Rev. La Rev. Can. des langues vivantes $\mathbf{4 7}$ (1991), no. 3, 486-496.

83. UPC. Consell Social, Marc per al disseny y la implantació dels plans d'estudis de grau a la UPC, Barcelona, 2008.
84. G. Urraza and J. M. Ortega, Diseño de una experiencia de aprendizaje por proyectos en la asignatura de Expresión Gráfica y diseño asistido por ordenador mediante grupos cooperativos, Rev. Form. e innovación Educ 2 (2009), 128-138.

85. M. Victoria, V. Matés and I. Cal, Valoración de la enseñanza: SEEQ, Rev. Form. e Innovación Educ. Univ. 3 (2010), no. 4, 182-193.

86. J. Winter, The effect of the flipped model on achievement in an introductory college physics course, Master's Thesis, Mississippi State University, 2013.

87. P. Won, The comparison between visual thinking using computer and conventional media in the concept generation stages of design, Autom. Constr. 10 (2001), no. 3, 319-325.

88. D. Woods, PBL: An evaluation of the effectiveness of authentic problem-based learning (aPBL), Chem. Eng. Educ. 46 (2012), no. 2, 135-144.

89. G. Wright, Student-centered learning in higher education, Int. J. Teach. Learn. High. Educ. 23 (2011), no. 3, 92-97.

90. E. Zancul, T. Sousa-Zomer and P. Cauchick-Miguel, Projectbased learning approach: Improvements of an undergraduate course in new product development, Producao. 27 (2017), no. Special issue, 1-14.

\section{AUTHOR BIOGRAPHIES}

Noelia Olmedo-Torre has a $\mathrm{PhD}$ in Multimedia Engineering from the Universitat Politècnica de Catalunya-BarcelonaTech (2007) and a degree in Telecommunications Engineering (1991). She has two postgraduate degrees: Interactive Multimedia Systems (1995) and University Education in Sciences, Technology, Engineering and Mathematics-STEM (2017). She is a professor at the Department of Graphic and Design Engineering (DGDE) of the Barcelona East School of Engineering (EEBE). Her research interests are the social aspects of engineering education, innovation in higher education, professional competencies, assessment tools, the promotion of teaching and learning improvement and, in general, educational innovation that contributes to teaching quality.

María Martínez Martínez has a PhD in Chemistry from the University of Barcelona and has been a professor in Chemical Engineering Department at Universitat Politècnica de Catalunya-BarcelonaTech since 1985. She teaches several subjects in Chemistry in the Industrial Scheduling Degree of ETSEIB (Industrial Engineering School of Barcelona) and of Barcelona East School of Engineering (EEBE). From June of 2007 until 2011 she was Teaching Innovation Assistant Manager of Education Sciences Institute (ICEUPC), which contributes to quality teaching enhancement by means of promoting improvement and teaching 
and learning innovation in higher education degrees. She belongs to several Communities of Practice (CoP) as part of the RIMA project (http://www.upc.edu/rima/) and is currently co-coordinating Avaluation CoP (GRAPA-RIMA-UPC), which is open to the entire university community through a virtual space that provides visibility of the dissemination and goals of the CoP. She has made several contributions in the scientific chemical sphere as well as in the field of teaching innovation. She was also a member of the steering committee of International Congress of University Teaching and Innovation (CIDUI) (http://cidui.upc. edu/) from 2007 until 2011.

Marta Peña received a degree in Industrial Engineering and the $\mathrm{PhD}$ degree in Mathematics from the Universitat Politècnica de Catalunya-BarcelonaTech, in 2001 and 2005, respectively. She is an
Associate Professor at the Department of Mathematics at the UPC since 2009, and she teaches at the Escola Tècnica Superior d'Enginyeria Industrial de Barcelona (ETSEIB). She has been deputy director of the Institute of Education Sciences at the UPC from 2016 to 2019. Her research interests are applied to mathematics and innovation in higher education, including social aspects of engineering education and student engagement.

How to cite this article: Olmedo-Torre N, Martínez MM, Peña M. Effectiveness of blended instructional design based on active learning in a graphic engineering course. Comput Appl Eng Educ. 2020;1-28. https://doi.org/10.1002/cae.22338 